\title{
Cyclic nucleotide-gated channels, calmodulin, adenylyl cyclase, and calcium/calmodulin-dependent protein kinase II are required for late, but not early, long-term memory formation in the honeybee
}

\author{
Yukihisa Matsumoto, 1,2,3,4,6 Jean-Christophe Sandoz, ${ }^{1,2,5}$ Jean-Marc Devaud, ${ }^{1,2}$ \\ Flore Lormant, ${ }^{1,2}$ Makoto Mizunami, ${ }^{3}$ and Martin Giurfa ${ }^{1,2,6}$ \\ ${ }^{1}$ Université de Toulouse, UPS, Research Centre on Animal Cognition, 31062 Toulouse Cedex 9, France; ${ }^{2}$ CNRS, Research Centre on \\ Animal Cognition, 31062 Toulouse Cedex 9, France; ${ }^{3}$ Graduate School of Life Science, Hokkaido University, Sapporo 060-0810, Japan
}

\begin{abstract}
Memory is a dynamic process that allows encoding, storage, and retrieval of information acquired through individual experience. In the honeybee Apis mellifera, olfactory conditioning of the proboscis extension response (PER) has shown that besides short-term memory (STM) and mid-term memory (MTM), two phases of long-term memory (LTM) are formed upon multiple-trial conditioning: an early phase (e-LTM) which depends on translation from already available mRNA, and a late phase (I-LTM) which requires de novo transcription and translation. Here we combined olfactory PER conditioning and neuropharmacological inhibition and studied the involvement of the NO-cGMP pathway, and of specific molecules, such as cyclic nucleotide-gated channels (CNG), calmodulin (CaM), adenylyl cyclase (AC), and $\mathrm{Ca}^{2+} /$ calmodulin-dependent protein kinase (CaMKII), in the formation of olfactory LTM in bees. We show that in addition to NO-cGMP and cAMP-PKA, CNG channels, CaM, AC, and CaMKII also participate in the formation of a I-LTM (72-h post-conditioning) that is specific for the learned odor. Importantly, the same molecules are dispensable for olfactory learning and for the formation of both MTM (in the minute and hour range) and e-LTM (24-h post-conditioning), thus suggesting that the signaling pathways leading to I-LTM or e-LTM involve different molecular actors.
\end{abstract}

Learning leads to cellular and molecular changes in the nervous system, which constitute the basis of memory, the capacity to encode, store, and retrieve information acquired through individual experience. Memory is a dynamic process organized in at least two different forms, short-term memory (STM) and long-term memory (LTM), exhibiting different temporal courses and distinct underlying molecular processes (Kandel 2001). Studies on both vertebrates and invertebrates (Bartsch et al. 1995; Yin and Tully 1996; Abel et al. 1997) showed that LTM formation requires an increase of the intracellular concentration of $3^{\prime}, 5^{\prime}$-cyclic adenosine monophosphate (cAMP) and the recruitment of cAMP-dependent protein kinase (PKA) that phosphorylates the transcription factor cAMP-responsive element-binding protein (CREB). Nitric oxide (NO)-cGMP $\left(3^{\prime}, 5^{\prime}\right.$-cyclic guanosine monophosphate) signaling is also involved in transcription-dependent plasticity, both in vertebrates (Lu et al. 1999) and invertebrates (Lewin and Walters 1999; Müller 2000; Kemenes et al. 2002). A link between the NO-cGMP system and CREB activation during transcriptiondependent long-term potentiation (LTP) has been found in mice (Lu et al. 1999).

\footnotetext{
${ }^{4}$ Present address: College of Liberal Arts and Science, Tokyo Medical and Dental University, 2-8-30 Kounodai, Ichikawa-shi, Chiba 272 0827, Japan

${ }^{5}$ Present address: Laboratory of Evolution, Genomes and Speciation, CNRS, 91198 Gif-sur-Yvette, France

${ }^{6}$ Corresponding authors

E-mail yukihisa.las@tmd.ac.jp

E-mail martin.giurfa@univ-tlse3.fr

Article is online at http://www.learnmem.org/cgi/doi/10.1101/Im.032037.113.
}

Insect models have largely contributed to our understanding of the molecular underpinnings of memory (e.g., Menzel 1999; Davis 2005; Margulies et al. 2005; Eisenhardt 2006; Schwärzel and Müller 2006; Busto et al. 2010). Among insects, the honeybee Apis mellifera has played an influential role in the study of memory as it provides both behavioral access to learning and memory in controlled laboratory protocols and invasive techniques that can trace behavioral plasticity to cellular and molecular levels (Menzel 1999, 2001; Giurfa 2007; Giurfa and Sandoz 2012). In a laboratory protocol termed the "olfactory conditioning of the proboscis extension reflex," harnessed honeybees learn to associate odorants with a sucrose reward (Takeda 1961; Bitterman et al. 1983; Giurfa and Sandoz 2012). When the antennae of a hungry, harnessed bee are touched with sucrose solution, the animal reflexively extends its proboscis to reach out to and suck the sucrose (proboscis extension reflex or PER). Neutral odorants blown to the antennae do not release such a reflex in naive animals. However, if an odorant is presented immediately before sucrose solution (forward pairing), an association is formed which enables the odorant to release the PER in a following test. This effect is clearly associative and constitutes a case of classical conditioning (Bitterman et al. 1983), i.e., the odorant acts as a conditioned stimulus

\footnotetext{
C) 2014 Matsumoto et al. This article is distributed exclusively by Cold Spring Harbor Laboratory Press for the first 12 months after the full-issue publication date (see http://learnmem.cshlp.org/site/misc/terms.xhtml). After 12 months, it is available under a Creative Commons License (AttributionNonCommercial 4.0 International), as described at http://creativecommons. org/licenses/by-nc/4.0/.
} 
(CS) and the sucrose solution as a rewarding, unconditioned stimulus (US).

One-trial conditioning induces a mid-term memory (MTM) that can be retrieved from minutes to $\sim 24 \mathrm{~h}$ after conditioning, and to an early-LTM (e-LTM) that can be retrieved from 24 to 48 $\mathrm{h}$ after conditioning. Multiple-trial conditioning also leads to MTM and e-LTM but induces, in addition, a late LTM (l-LTM) that can be retrieved three or more days after conditioning (Menzel 1999; Eisenhardt 2006; Schwärzel and Müller 2006). While e-LTM depends on translation from already available mRNA, l-LTM requires de novo transcription and translation (Menzel 1999; Schwärzel and Müller 2006).

Multiple-trial conditioning, which induces e- and l-LTM, promotes prolonged PKA activation mediated by NO, while onetrial conditioning, which induces only e-LTM, promotes transient PKA activation that is not mediated by NO signaling (Müller 2000). How precisely cAMP and NO-cGMP pathways are linked to each other in LTM formation, and if and how they mediate different memories, remains unclear. A possible link has been suggested in the cricket Gryllus bimaculatus, where NO-cGMP signaling was proposed to activate cAMP-mediated signaling via cyclic nucleotide-gated cation channels (CNG channels) and $\mathrm{Ca}^{2+} / \mathrm{cal}-$ modulin (CaM), thereby leading to LTM (Matsumoto et al. 2006). Here we studied the implication of these molecules and signaling pathways in l-LTM formation in the bee, taking advantage of the olfactory conditioning of PER. We also determined whether activations of adenylyl cyclases (ACs), which have been proposed as coincidence detectors integrating CS and US inputs, thereby facilitating associative learning and memory (Anholt 1994; Gervasi et al. 2010), and of the $\mathrm{Ca}^{2+} / \mathrm{CaM}$-dependent protein kinase II (CaMKII) are crucial events underlying LTM formation, as found both in vertebrates (Anholt 1994; Makhinson et al. 1999; Wang et al. 2004; Shan et al. 2008) and other invertebrates (Akalal et al. 2010; Gervasi et al. 2010; Chen et al. 2012; Malik et al. 2013).

We conditioned and tested 6991 honeybees, thereby providing the most extensive data set ever produced in experiments on PER conditioning. We determined the effect of antagonists of NO synthase (NOS), sGC, CNG channels, CaM, CaMKII, and AC on olfactory l-LTM measured $3 \mathrm{~d}(72 \mathrm{~h})$ after conditioning. We also determined the specificity of these molecules for l-LTM by comparing the effects of their pharmacological antagonists 3 $\mathrm{h}$ (MTM), $24 \mathrm{~h}$ (e-LTM), and $72 \mathrm{~h}$ after conditioning. We show that these molecules are required for odor-specific l-LTM but are neither necessary for earlier memory phases nor for learning.

\section{Results}

\section{Experiment 1: Noninjected bees learn odor-sucrose associations and exhibit significant memory retention $3 \mathrm{~d}$ after conditioning}

We first verified that noninjected bees exhibit fast appetitive olfactory learning and robust memory (LTM) retention $3 \mathrm{~d}$ after conditioning. Bees were conditioned either with 1-nonanol $(n=74)$ or 2-hexanol $(n=74)$. In both groups, acquisition and LTM retention performances were similar (ANOVA for repeated measurements: factor group, acquisition, $F_{(1,146)}=1.16, P=0.28$; retention, $F_{(1,146)}=0.88, P=0.35$; group $\times$ trial interaction, acquisition, $F_{(2,292)}=0.02, P=0.98$; retention, $F_{(1,146)}=0.03, P=$ 0.87 ) so that data of these groups were pooled. In all further experiments, no differences between bees conditioned with 1-nonanol or 2-hexanol were detected ( $P>0.05$ in all cases). Data were, therefore, pooled and presented as a single group.

Pooled acquisition and retention performances of noninjected bees exhibited the typical response patterns observed in olfactory PER conditioning (see Fig. 1). Acquisition was fast and

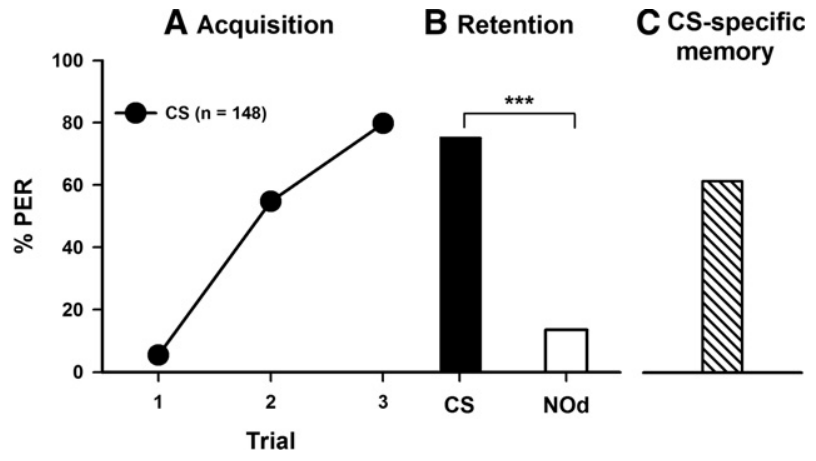

Figure 1. Olfactory acquisition and 3-d memory retention in honeybees. Bees were conditioned in three trials in which either 1-nonanol or 2-hexanol was used as conditioned stimulus (CS) paired with sucrose solution. $(A)$ Acquisition was similar and effective in bees trained with these two odorants. $(B)$ Three days after training, both groups were tested both with the CS and with a novel odorant (NOd) (1-nonanol for bees trained with 2-hexanol and vice versa). Bees responded to the CS and showed low generalization to the novel odor. Responses to the CS and to the novel odor were identical in both groups. (C) Percentage of bees exhibiting CS-specific memory, i.e., responding to the CS and not to the NOd during retention $3 \mathrm{~d}$ after conditioning. $\left(^{* * *}\right) P<0.001$.

highly significant $\left(F_{(2,294)}=183.65, P<0.00001\right)$, reaching $80 \%$ of conditioned responses at the last acquisition trial (Fig. 1A). Three days after conditioning, bees exhibited robust LTM retention (Fig. 1B) evinced by highly significant responses to the CS (75\% conditioned responses) and low generalization responses to the NOd (13.5\%). Responses to the CS were significantly higher than those to the NOd (McNemar test, $\chi^{2}=89.01, \mathrm{df}=1, P<$ 0.00001). CS-specific retention, defined as the proportion of bees which correctly responded to the CS and not to the NOd, was $61.5 \%$ (Fig. 1C).

Thus, noninjected bees learned the odorants efficiently and showed significant l-LTM retention $3 \mathrm{~d}$ after conditioning.

\section{Experiment 2: Inhibition of protein synthesis and NO-cGMP signaling impairs I-LTM retention}

Previous studies have demonstrated that NO-cGMP signaling and protein synthesis are involved in LTM formation in honeybees (Müller 1996, 2000; Wüstenberg et al. 1998; Schwärzel and Müller 2006). We thus verified that in our experimental conditions blocking the NO-cGMP signaling cascade and protein synthesis impairs LTM retention $3 \mathrm{~d}$ after conditioning.

NO-mediated activation of sGC leads to the synthesis of the second messenger cGMP. We blocked the NO-cGMP signaling pathway via injection of L-NAME (NOS-inhibitor, $n=68$ ) or ODQ (sGC inhibitor, $n=74$ ) and protein synthesis via injection of CHX $(n=69)$. Here and in the following experiments, injections were performed into the hemolymph of the thorax and, unless explicitly stated otherwise, $20 \mathrm{~min}$ before conditioning.

The doses of L-NAME and ODQ were chosen according to previous works in which these drugs acted as efficient NOS and sGC inhibitors in the honeybee nervous system (Müller 1996, 2000). The dose of CHX was three times larger than that reported as ineffective to block memory in bees (Table 1; Wittstock et al. 1993). None of the concentrations used induced significant $(>5 \%)$ mortality in bees. Two control groups were injected with saline ( $n=70$ ) or saline containing 0.1\% DMSO (D saline, $n=62$ ).

Figure 2A shows the acquisition performance of the different groups. The two saline groups (saline and $\mathrm{D}$ saline) did not differ significantly from each other $\left(F_{(1,130)}=0.39, P=0.54\right)$ and exhibited a nonsignificant group $\times$ trial interaction $\left(F_{(2,260)}=0.30, P=\right.$ 
Table 1. Drugs and doses used in the present study

\begin{tabular}{|c|c|c|c|c|}
\hline Drug & Target & $\begin{array}{l}\text { Concentration } \\
\qquad(\mathrm{mM})\end{array}$ & $\begin{array}{c}\text { Dose } \\
(\mathrm{mg} / \mathrm{kg})\end{array}$ & Figure \\
\hline L-NAME (L-NG-nitroarginine methyl ester) & NOS inhibitor & 0.5 & 1.3 & Figure 2 \\
\hline ODQ (1H-[1,2,4]oxadiazolo[4,3-a]quinoxalin-1-one) & sGC inhibitor & 0.5 & 0.9 & Figure 2 \\
\hline $\begin{array}{l}\mathrm{CHX} \text { (cycloheximide or 4-[(2R)-2-[(1S,3S,5S)-3,5- } \\
\text { dimethyl-2-oxocyclohexyl]-2-hydroxyethyl]piperidine- } \\
\text { 2,6-dione) }\end{array}$ & $\begin{array}{l}\text { Protein synthesis } \\
\text { inhibitor }\end{array}$ & 50 & 140.7 & Figure 2 \\
\hline \multirow[t]{3}{*}{ L-DIL (L-cis-diltiazem hydrochloride) } & GNG channel & 0.2 & 0.9 & Figure 3 \\
\hline & inhibitor & 0.5 & 2.3 & Figure 3 \\
\hline & & 1.0 & 4.5 & Figures $3,7,8$ \\
\hline \multirow{3}{*}{$\begin{array}{l}\text { W-7 (N-[6-aminohexyl]-5-chloro-1- } \\
\text { naphthalenesulfonamide hydrochloride) }\end{array}$} & CaM antagonist & 0.2 & 0.8 & Figure 4 \\
\hline & & 0.5 & 1.9 & Figure 4 \\
\hline & & 1.0 & 3.8 & Figures $4,7,8$ \\
\hline \multirow{2}{*}{$\begin{array}{l}\text { TFP (trifluoperazine or 10-[3-(4-methyl-1- } \\
\text { piperazinyl)propyl]-2-[trifluoromethyl]-10H- } \\
\text { phenothiazine dihydrochloride) }\end{array}$} & CaM antagonist & 0.5 & 1.9 & Figure 4 \\
\hline & & 5.0 & 19.4 & Figure 4 \\
\hline \multirow{2}{*}{$\begin{array}{l}\text { R24571 (calmidazolium or 3-[bis(4- } \\
\text { chlorophenyl)methyl]-1-[2-(2,4-dichlorophenyl)-2- } \\
\text { [(2,4-dichlorophenyl)methoxy]ethyl]-1H-imidazolium, } \\
\text { monochloride) }\end{array}$} & CaM antagonist & 0.5 & 3.4 & Figure 4 \\
\hline & & 5.0 & 34.4 & Figure 4 \\
\hline \multirow{2}{*}{$\begin{array}{l}\mathrm{KN}-62 \text { (1-[N,O-bis-(5-isoquinolinesulphonyl)- } N \text {-methyl-L- } \\
\text { tyrosyl] }-4 \text { - phenylpiperazine) }\end{array}$} & CaMKII inhibitor & 0.5 & 3.6 & Figure 5 \\
\hline & & 2.0 & 14.4 & Figures $5,7,8$ \\
\hline \multirow[t]{3}{*}{ DDA $\left(2^{\prime}, 5^{\prime}\right.$-dideoxyadenosine $)$} & Adenylyl cyclase & 0.5 & 1.2 & Figure 6 \\
\hline & inhibitor & 1.0 & 5.9 & Figure 6 \\
\hline & & 5.0 & 11.8 & Figures $6,7,8$ \\
\hline SQ 22536 (9-[tetrahydrofuryl]-adenine) & $\begin{array}{l}\text { Adenylyl cyclase } \\
\text { inhibitor }\end{array}$ & 0.1 & 0.1 & Figures 6,7 \\
\hline $\begin{array}{l}\text { MDL 12330A (cis- } N \text {-[2-phenylcyclopentyl]-azacyclotridec- } \\
\text { 1-en-2-amine) }\end{array}$ & $\begin{array}{l}\text { Adenylyl cyclase } \\
\text { inhibitor }\end{array}$ & 0.1 & 0.2 & Figures 6,7 \\
\hline
\end{tabular}

0.74) so that their results were pooled and presented as a single curve ("saline," $n=132$ ) (Fig. 2A). Acquisition did not differ among all four groups $\left(F_{(3,373)}=0.20, P=0.90\right)$ and the interaction was also not significant $\left(F_{(6,746)}=0.22, P=0.97\right)$, showing that all bees learned to respond to the CS in a similar way. Thus, none of the three drugs (L-NAME, ODQ, and CHX) affected acquisition.

In the 3 -d retention tests, the two saline groups (saline and D saline) did not differ significantly from each other (CS and NOd responses, $\left.F_{(1,130)}=0.32, P=0.58\right)$ and exhibited a nonsignificant interaction $\left(F_{(1,130)}=0.20, P=0.65\right)$ so that their results were pooled again and presented as a single saline group ("saline," $n=132$ ) (Fig. 2B). Bees in this control group responded significantly more to the CS than to the NOd $\left(\chi^{2}=75.01, \mathrm{df}=1\right.$, $P<0.00001)$ and exhibited a high CSspecific memory $(57.7 \%)$. Bees injected with CHX, L-NAME, or ODQ showed fewer conditioned responses (between $25.7 \%$ and $36.2 \%$ ) than the control group, inducing a significant heterogeneity in retention performance among the four groups (CS responses, $F_{(3,339)}=$ 10.93, $P<0.0001)$. This heterogeneity was due to the fact that CS responses of the control group were significantly higher than those of the drug-injected groups (Tukey test, $P<0.05$ for all comparisons), thus indicating that these drugs induced a similar impairment of 3-d CS retention. CS responses of the CHX, L-NAME, and ODQ groups were statistically indistinguishable $(P>0.50$ for all comparisons). Responses to the NOd were equally low in all groups including saline bees (NOd responses, $F_{(3,339)}=0.56, P=0.65$ ). Although reduced, CS responses were significantly higher than NOd responses in all drug-injected groups (L-NAME, $\chi^{2}=13.47$, $\mathrm{df}=1, P<0.0005 ;$ ODQ $\chi^{2}=12.50, \mathrm{df}=1, P<0.0005 ; \mathrm{CHX}$, $\left.\chi^{2}=15.43, \mathrm{df}=1, P<0.0002\right)$, thus indicating that CS retrieval was still possible. Indeed, CS-specific memory was $28.99 \%$, $26.47 \%$, and $22.97 \%$ for CHX-, L-NAME-, and ODQ-injected bees, respectively (Fig. 2C). CS-specific memory differed between

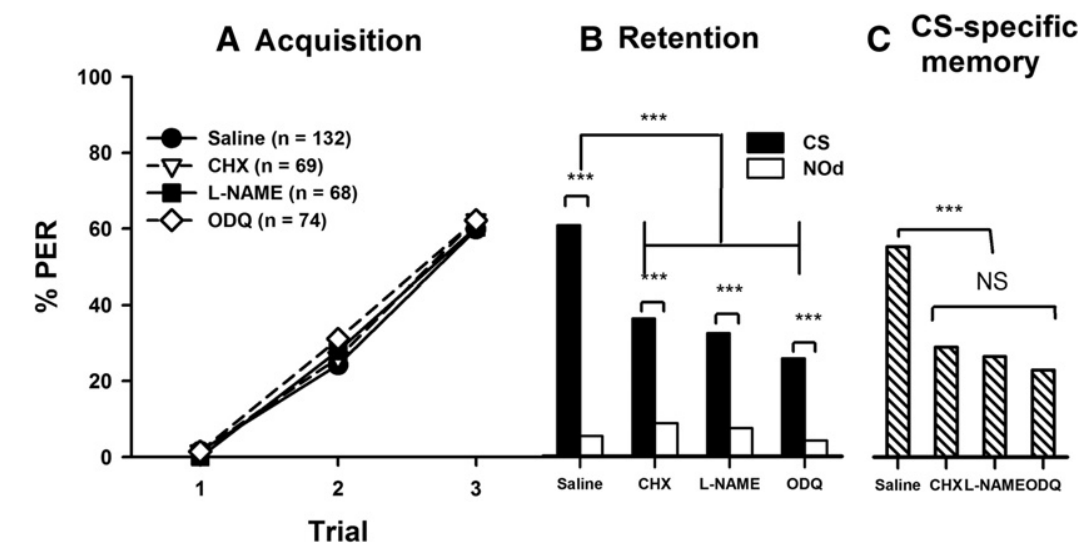

Figure 2. Inhibition of translation and of the NO-cGMP pathway impairs 3-d retention. Twenty minutes before conditioning, bees received an injection $(1 \mu \mathrm{L})$ of either saline solution (saline), the protein synthesis-inhibitor CHX $(50 \mathrm{mM})$, the NOS-inhibitor L-NAME $(0.5 \mathrm{mM})$, or the sGC-inhibitor ODQ $(0.5 \mathrm{mM})$. Bees were conditioned either with 1-nonanol or with 2-hexanol; performances of both subgroups did not differ significantly and their data were pooled. (A) All groups showed similar and effective acquisition. (B) In the 3-d retention test, all drug-injected groups were significantly impaired in their CS response (black bars) when compared to the saline group (control). Yet, they still exhibited a CS-specific memory as responses to the novel odorant (NOd, white bars) were significantly lower in all groups. Performance of all three drug-injected groups (CHX, L-NAME, ODQ) was equivalent. (C) Percentage of bees exhibiting CS-specific memory, i.e., responding to the CS and not to the NOd during retention $3 \mathrm{~d}$ after conditioning. $\left({ }^{* * *}\right) P<0.001$, (NS) nonsignificant. 
saline-injected and drug-injected bees (Tukey test for multiple comparisons between proportions, $q_{\infty, 4}>3.633$ for all three comparisons, $P<0.001$ ) but not between drug-injected bees $\left(q_{\infty, 4}>3.633\right.$ for all three comparisons, NS).

Thus, inhibition of protein synthesis via CHX and of NOcGMP signaling via L-NAME and ODQ impairs l-LTM retention in honeybees.

\section{Experiment 3: Inhibition of CNG channels impairs I-LTM retention}

CNG channels are $\mathrm{Ca}^{2+}$-permeable channels activated by cAMP and/or cGMP. They are crucial for sensory transduction at the level of olfactory receptors (Broillet and Firestein 1996) and for discrimination of olfactory stimuli in the presence of an adapting background odor in mammals (Kelliher et al. 2003). Their involvement in olfactory learning and memory has been postulated in crickets (Matsumoto et al. 2006), but has not been studied so far in any other insect model. We thus examined the effect of L-DIL, a CNG channel inhibitor (Kaupp and Seifert 2002), on olfactory learning and memory in honeybees (Fig. 3). Bees were injected either with saline $(n=62)$ or with L-DIL delivered at three different concentrations, $0.2 \mathrm{mM}(n=57), 0.5 \mathrm{mM}(n=64)$, or 1 $\mathrm{mM}(n=59)$ (Table 1$)$.

All four groups exhibited similar acquisition performances $\left(F_{(3,238)}=0.65, P=0.59\right.$; interaction, $\left.F_{(6,476)}=0.30, P=0.94\right)$ and reached $56.5 \%-67.2 \%$ of conditioned responses at the third trial (Fig. 3A), thus showing that L-DIL injection did not affect acquisition. Retention performances varied depending on treatment (ANOVA performed on CS and NOd responses, $F_{(3,238)}=$ 3.84, $P<0.02$ ) (Fig. 3B). CS responses decreased significantly from $54.8 \%$ in the saline group to $18.6 \%$ in the group injected with $1 \mathrm{mM}$ L-DIL $\left(F_{(3,238)}=7.61, P<0.0001\right)$. CS responses did not differ between the saline group and the group injected with the lowest L-DIL dose $(0.2 \mathrm{mM}$; Tukey test, $P=0.32)$, but they were significantly different between the saline group and the groups injected with the intermediate and the highest L-DIL doses (L-DIL 0.5 and $1 \mathrm{mM}, P=0.006$ and $P<0.0001$, respectively). A

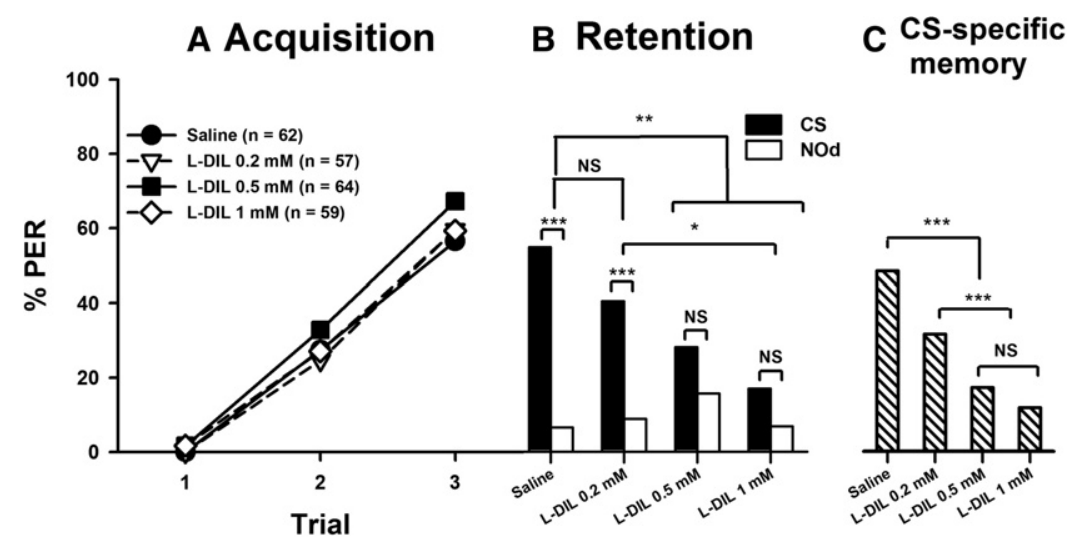

Figure 3. Inhibition of CNG channels impairs 3-d retention. Twenty minutes before conditioning, bees received an injection $(1 \mu \mathrm{L}$ ) of either saline solution (saline) or one of three different concentrations $(0.2 \mathrm{mM}, 0.5 \mathrm{mM}$, or $1 \mathrm{mM}$ ) of the CNG-channel-inhibitor L-DIL. Bees were conditioned either with 1-nonanol or with 2-hexanol; performances of both subgroups did not differ significantly and their data were pooled. (A) All groups showed similar and effective acquisition. (B) In the 3-d retention test, the groups injected with the intermediate $(0.5 \mathrm{mM})$ and the highest $(1 \mathrm{mM})$ dose of L-DIL exhibited a significant decrease of CS responses with respect to the saline control. In these two groups, there was no significant difference between the response to the CS (black bars) and the response to the NOd (white bars), thus indicating a loss of the CS-specific memory. (C) Percentage of bees exhibiting CS-specific memory, i.e., responding to the CS and not to the NOd during retention $3 \mathrm{~d}$ after conditioning. $\left(^{*}\right) P<0.05,\left(^{* *}\right) P<0.01,\left(^{* * *}\right) P<0.001$, (NS) nonsignificant. dose-dependent drug effect was found as the highest L-DIL dose $(1 \mathrm{mM})$ induced the lowest level of CS responses while the lowest CS responses of the $0.5 \mathrm{mM}$ L-DIL group were at an intermediate level. By contrast, responses to the novel odorant did not differ significantly between groups (NOd responses, $F_{(3,238)}=1.33, P=$ $0.26)$. Significant discrimination between the CS and the NOd was found in the saline group $\left(\chi^{2}=28.03, \mathrm{df}=1, P<0.0001\right)$ and in the group with the lowest $(0.2 \mathrm{mM})$ L-DIL dose $\left(\chi^{2}=\right.$ 16.06, $\mathrm{df}=1, P<0.001)$. Discrimination was nonsignificant for the groups injected with the intermediate $(0.5 \mathrm{mM})$ dose $\left(\chi^{2}=\right.$ $3.50, \mathrm{df}=1, P=0.06)$ and the highest L-DIL $(1 \mathrm{mM})$ dose $\left(\chi^{2}=\right.$ $3.13, \mathrm{df}=1, P=0.08)$. CS-specific memory was, respectively, $17.19 \%$ and $11.8 \%$ for these groups while it was $48.39 \%$ and $31.58 \%$ for the saline group and for the group with the lowest tween saline-injected and drug-injected bees $\left(q_{\infty, 4}>3.633\right.$ for all three comparisons, $P<0.001)$ and also between bees injected doses $\left(q_{\infty, 4}>3.633\right.$ for both comparisons, $\left.P<0.01\right)$. No difwith L-DIL 0.5 and $1 \mathrm{mM}\left(q_{\infty, 4}<3.633, \mathrm{NS}\right)$.

Thus, inhibition of CNG channels impairs l-LTM retention in

\section{Experiment 4: Inhibition of CaM impairs} I-LTM retention

$\mathrm{CaM}$ is a major $\mathrm{Ca}^{2+}$-binding protein found in the central nervous system. Although a large number of studies have investigated the MAPK) on learning and memory, there are relatively few reports (he effects of direct inhibition of CaM (Malenka et al. . We investigated the effect of CaM inhibition on olfacdiffearning and memory in honeybees using three structurally ferent concentrations (Fig. 4).

Bees were injected with saline or a CaM antagonist before conditioning. For all three CaM-antagonist injected groups, acquisition was similar and fast and did not differ from that of their corresponding control groups (W-7, $F_{(3,317)}=0.48, P=0.70 ;$ TFP, $F_{(2,188)}=$ $1.11, P=0.33 ; \mathrm{R} 24571, F_{(2,206)}=0.90$, $P=0.41$ ) (Fig. 4A,D,G). At the third conditioning trial, bees of all groups reached similar levels of conditioned responses $(55.7 \%-69.4 \%)$. Thus, injection of the three different CaM antagonists did not affect acquisition.

Figure 4B shows 3-d retention performances after $\mathrm{W}-7$ injection. There was a significant variation in retention levels among groups (CS and NOd responses, $\left.F_{(3,317)}=7.96, P<0.0001\right)$. The level of CS responses was significantly reduced in W-7 injected bees with respect to that of the saline group (CS responses, $\left.F_{(3,317)}=16.21, \quad P<0.00001\right)$, but the three W-7 injected groups did not differ in their levels of CS responses (Tukey test, $P>0.40$ for all comparisons). Response levels to the NOd did not vary among groups (NOd responses, $F_{(3,317)}=$ 


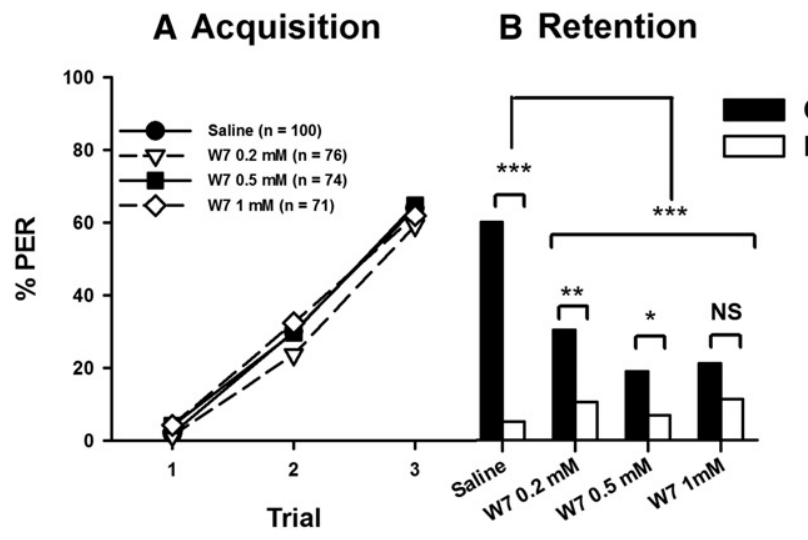

\section{CS-specific memory \\ CS}

NOd

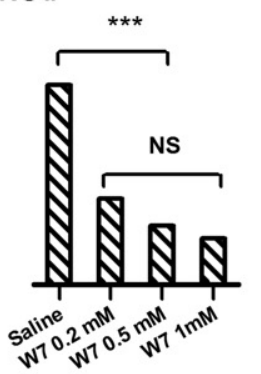

D Acquisition

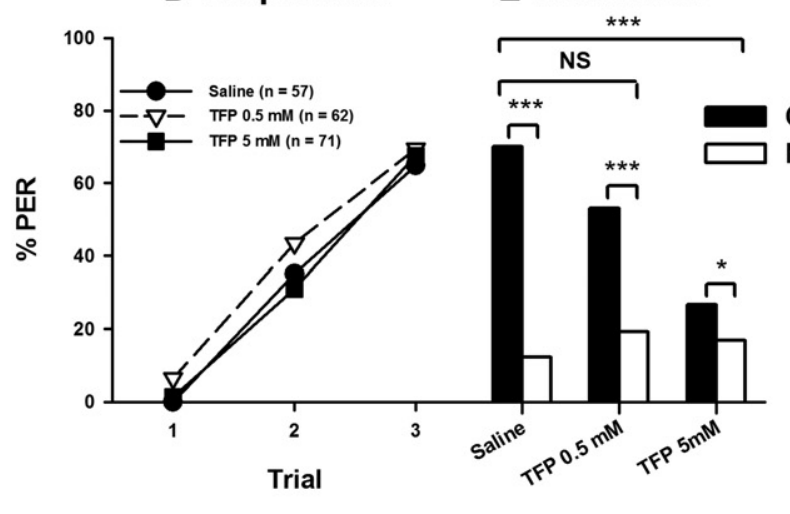

\section{E Retention}

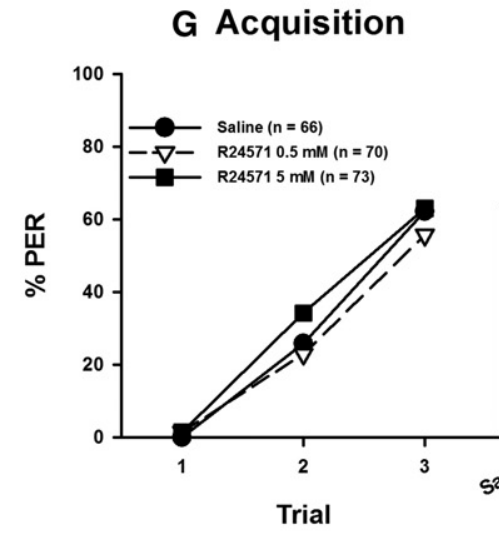

\section{H Retention}

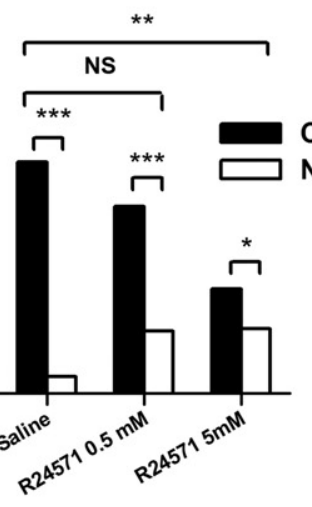

\section{F CS-specific} memory
NOd

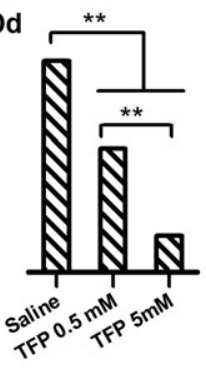

\section{CS-specific memory}

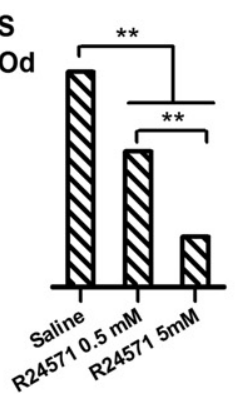

Figure 4. Inhibition of CaM impairs 3-d retention. Twenty minutes before conditioning, bees received an injection of either saline solution (saline) or one of two to three different concentrations of the CaM antagonists W-7 $(A, B)$, TFP $(C, D)$, or R24571 $(E, F)$. Bees were conditioned either with 1-nonanol or with 2-hexanol; performances of both subgroups did not differ significantly and their data were pooled. $(A, D, G)$ All groups showed similar and effective acquisition. $(B, E, H)$ In the 3 -d retention test, all groups injected with the highest drug doses showed a significant decrease of CS responses with respect to the saline control, as well as to those treated with lower doses of W-7. Drug effects were dose-dependent. In the group injected with $1 \mathrm{mM} \mathrm{W-7,} \mathrm{there} \mathrm{was} \mathrm{no} \mathrm{significant} \mathrm{difference} \mathrm{between}$ the responses to the CS (black bars) and to the NOd (white bars), indicating a loss of CS-specific memory. $(C, F, I)$ Percentage of bees exhibiting CS-specific memory, i.e., responding to the CS and not to the NOd during retention $3 \mathrm{~d}$ after conditioning. $\left(^{*}\right) P<0.05,\left(^{* *}\right) P<0.01,\left({ }^{* * *}\right) P<0.001$, (NS) nonsignificant.

$1.01, P=0.39)$. The saline group responded significantly more to the CS than those to the NOd $\left(\chi^{2}=53.02, \mathrm{df}=1, P<0.0001\right)$. Discrimination was also significant in the groups injected with the lowest $(0.2 \mathrm{mM})$ and the intermediate $(0.5 \mathrm{mM}) \mathrm{W}-7$ doses $\left(\chi^{2}=9.33, \mathrm{df}=1, P<0.005\right.$ and $\chi^{2}=$ 4.27, $\mathrm{df}=1, P<0.05$, respectively) but not in the group injected with the highest dose $\left(1 \mathrm{mM}, \chi^{2}=3.27, \mathrm{df}=1, P=0.07\right)$. The proportion of bees exhibiting CS-specific memory was $55 \%$ in the saline group and decreased to $23.68 \%(0.2 \mathrm{mM})$, $16.22 \%(0.5 \mathrm{mM})$, and $12.68 \%(1 \mathrm{mM})$ in the $\mathrm{W}-7$ injected groups (Fig. 4C). CSspecific memory differed between salineinjected and drug-injected bees $\left(q_{\infty, 4}>\right.$ 3.633 for all three comparisons, $P<$ 0.001 ) but not between drug-injected bees $\left(q_{\infty, 4}<3.633\right.$ for all three comparisons, NS).

Figure 4E shows 3-d retention performances after TFP injection. There was a significant variation in retention among groups (CS and NOd responses, $\left.F_{(2,188)}=4.74, \quad P<0.01\right) . \quad$ Specifically, the level of CS responses varied significantly among groups (CS responses, $\left.F_{(2,188)}=13.33, P<0.0001\right)$. While the lower TFP dose $(0.5 \mathrm{mM})$ did not induce any significant drop in CS responses compared to the control group (Tukey test, $P=0.16)$, the higher dose $(5 \mathrm{mM})$ decreased CS responses, and rendered them significantly different both from those of the control group $(P<0.0005)$ and of the group injected with the lower TFP dose $(P<0.005)$. Responses to the NOd did not differ among groups (NOd responses, $\left.F_{(2,188)}=0.60, P=0.55\right)$. All groups significantly discriminated the CS from the NOd (saline, $\chi^{2}=31.03$, $\mathrm{df}=1, P<0.0001 ;$ TFP $0.5 \mathrm{mM}, \chi^{2}=$ 19.05, $\mathrm{df}=1, P<0.0001$; TFP $5 \mathrm{mM}$, $\left.\chi^{2}=5.15, \mathrm{df}=1, P<0.05\right)$, but the proportion of bees exhibiting CS-specific memory decreased with TFP dose (saline group, 57.90\%; TFP $0.5 \mathrm{mM}, 33.87 \%$; TFP 5 mM, 9.86\%) (Fig. 4F). CS-specific memory differed between saline-injected and drug-injected bees $\left(q_{\infty, 3}>3.314\right.$ for both comparisons, $P<0.01)$ and also between bees injected with the lowest and the highest TFP doses $\left(q_{\infty, 3}>3.314\right.$, $P<0.01$ ).

Figure $4 \mathrm{H}$ shows 3 -d retention performances after R24571 injection. There was no significant variation in retention among groups (CS and NOd responses, $\left.F_{(2,206)}=1.91, P=0.15\right)$. Yet, the level of CS responses varied significantly among groups (CS responses, $F_{(2,206)}=$ 5.82, $P<0.005)$. The lower R24571 dose $(0.5 \mathrm{mM})$ did not induce any significant drop in CS responses with respect to the control group (Tukey test, $P=0.48$ ). In contrast, the higher dose $(5 \mathrm{mM})$ decreased CS responses and rendered them significantly different from those of the saline group $(P<$ $0.005)$ but not from those of the group injected with the lower R24571 dose $(P=0.07)$. Responses to the NOd differed among groups (NOd responses, $F_{(2,206)}=3.32, P<0.05$ ) as they increased 
with the dose of R24571. All groups significantly discriminated the CS from the NOd (saline, $\chi^{2}=37.03$, df $=1, P<0.0001$; R24571 $0.5 \mathrm{mM}, \chi^{2}=18.89, \mathrm{df}=1, P<0.0001$; R24571 $5 \mathrm{mM}$, $\chi^{2}=4.08, \mathrm{df}=1, P<0.05$ ), but the proportion of bees exhibiting CS-specific memory decreased with increasing R24571 doses (saline group, 59.09\%; R24571 $0.5 \mathrm{mM}, 37.14 \%$; and R24571 5 $\mathrm{mM}, 13.70 \%$ ) (Fig. 4I). CS-specific memory differed between saline-injected and drug-injected bees $\left(q_{\infty, 3}>3.314\right.$ for both comparisons, $P<0.01)$ and also between bees injected with the lowest and the highest R24571 doses $\left(q_{\infty, 3}>3.314, P<0.01\right)$.

All in all, the three CaM antagonists significantly decreased 3 -d retention by reducing responses to the CS when injected at a high dose.

\section{Experiment 5: Inhibition of CaMKII impairs I-LTM retention}

The $\mathrm{Ca}^{2+} / \mathrm{CaM}$-dependent protein kinase II (CaMKII) has been linked to neuronal plasticity associated with long-term potentiation as well as with structural synaptic plasticity (Micheau and Riedel 1999). Previous work in adult honeybees has shown that the single CaMKII gene found in honeybees is strongly expressed in the mushroom bodies (MBs) (Kamikouchi et al. 2000), brain centers associated with sensory integration, learning, and memory formation (Giurfa 2007; Giurfa and Sandoz 2012). Moreover, the activated (phosphorylated) form of the protein, pCaMKII, is predominantly concentrated in these structures in the adult bee brain (Pasch et al. 2011). We studied the effect of KN-62, a CaMKII inhibitor (Enslen et al. 1994), on olfactory acquisition and 3-d retention in honeybees.

Before conditioning, bees were injected either with saline $(n=65)$ or with one of two different concentrations of KN-62, $0.5 \mathrm{mM}(n=61)$ or $2 \mathrm{mM}(n=71)$. Figure $5 \mathrm{~A}$ shows that there was no significant variation in acquisition among groups $\left(F_{(2,194)}=0.35, P=0.71\right)$. In all three groups acquisition was similar and fast and, irrespective of treatment, all bees reached a similar level of conditioned responses at the third conditioning trial (between $57.4 \%$ and $67.6 \%$ ). Thus, injection of $\mathrm{KN}-62$ did not affect acquisition.

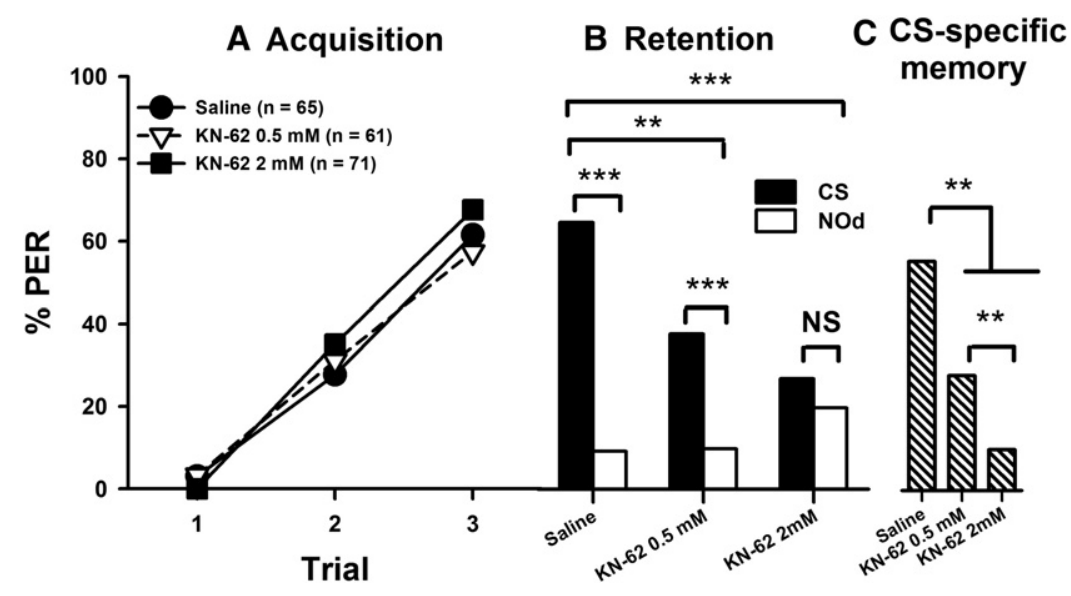

Figure 5. Inhibition of CaMKII impairs 3-d retention. Twenty minutes before conditioning, bees received an injection of either saline solution (saline) or one of two different concentrations $(0.5 \mathrm{mM}$ or $2 \mathrm{mM}$ ) of KN-62, a CaMKII-inhibitor. (A) All groups showed similar and effective acquisition. (B) In the 3-d retention test, the two groups injected with $\mathrm{KN}-62$ showed a significant decrease of CS responses with respect to the saline control. In the group injected with $2 \mathrm{mM} \mathrm{KN}-62$, there was no significant difference between the responses to the CS (black bars) and to the NOd (white bars), indicating a loss of CS-specific memory. (C) Percentage of bees exhibiting CS-specific memory, i.e., responding to the CS and not to the NOd during retention $3 \mathrm{~d}$ after conditioning. $\left({ }^{* *}\right) P<0.01,\left({ }^{* *}\right) P<0.001$, (NS) nonsignificant.
Figure $5 \mathrm{~B}$ shows performances during the 3 - $\mathrm{d}$ retention tests. There were significant differences among groups (CS and NOd responses, $\left.F_{(2,194)}=3.34, P<0.05\right)$. Specifically, groups differed significantly in their level of CS responses (CS responses, $\left.F_{(2,194)}=11.43, P<0.0001\right)$ as saline-injected bees responded more to the CS than the two groups injected with $\mathrm{KN}-62$ (Tukey test, $P<0.005$ in both cases); the two groups injected their CS responses $(P=0.38)$. No significant variation in the groups' responses to the NOd were detected (NOd responses, $\left.F_{(2,194)}=2.08, P=0.13\right)$. While the control group and the group injected with the lower KN-62 dose exhibited significant discrimination between CS and NOd (saline, $\chi^{2}=34.03, \mathrm{df}=1, P<$ $0.0001 ; \mathrm{KN}-620.5 \mathrm{mM}, \chi^{2}=15.06, \mathrm{df}=1, P<0.001$ ), the group injected with the higher KN-62 dose did not show any discrimination between these odorants $\left(\chi^{2}=1.78, \mathrm{df}=1, P=0.18\right)$. The proportion of bees that exhibited CS-specific memory decreased from $55.39 \%$ in the control group to $27.87 \%$ in the group injected with $\mathrm{KN}-620.5 \mathrm{mM}$, and to $9.86 \%$ in the group injected with KN-62 2 mM. CS-specific memory differed between saline-injectdrug-injected bees $\left(q_{\infty, 3}>3.314\right.$ for both comparisons, $<0.01)$ and also between bees injected with the lowest and highest $\mathrm{KN}-62$ doses $\left(q_{\infty, 3}>3.314, P<0.01\right)$

Thus, inhibition of a CaMKII significantly impaired l-LTM by Experiment 6: Inhibition of AC impairs I-LTM retention

Studies in a number of animal models have shown that the cAMP signaling pathway, including some adenylyl cyclases (AC), is crucial for the formation of LTM (Wong et al. 1999; Kandel 2001; Poser and Storm 2001). In honeybees, pharmacological inhibition of PKA, the primary target of cAMP, impairs LTM (Müller 2000). However, whether direct inhibition of AC affects honeybee learning and memory remains to be determined. In order to study the implication of AC in olfactory acquisition and 3-d retention, we injected bees $20 \mathrm{~min}$ before training with saline $(n=100)$ or with 2', 5'-dideoxyadenosine (DDA), a P-site specific AC inhibitor (Bhattacharya et al. 2004). DDA was injected at three different concentrations, $0.5 \mathrm{mM}(n=65), 1 \mathrm{mM}(n=66)$, and 5 $\mathrm{mM}(n=69)$.

Figure $6 \mathrm{~A}$ shows that acquisition was fast and similar in all groups $\left(F_{(3,297)}=0.09, P=0.97\right)$. At the third conditioning trial, bees reached a level of conditioned responses that was between $63.1 \%$ and $69.7 \%$. Thus, injection of the AC inhibitor DDA did not impair olfactory acquisition.

The performances of the different groups in 3-d retention tests are shown in Figure 6B. Retention differed significantly among groups (CS and NOd responses, $\left.\quad F_{(3,297)}=2.90, \quad P<0.05\right)$; in particular, responses to the CS varied significantly (CS responses, $F_{(3,297)}=$ 5.99, $P<0.001)$ as the saline group exhibited significantly more CS responses than all DDA-injected groups (Tukey test, $P<0.05$ for all three comparisons). DDA-injected groups did not differ from each other in their CS responses $(P>0.78$ for all three comparisons). Responses to the novel odorant were 

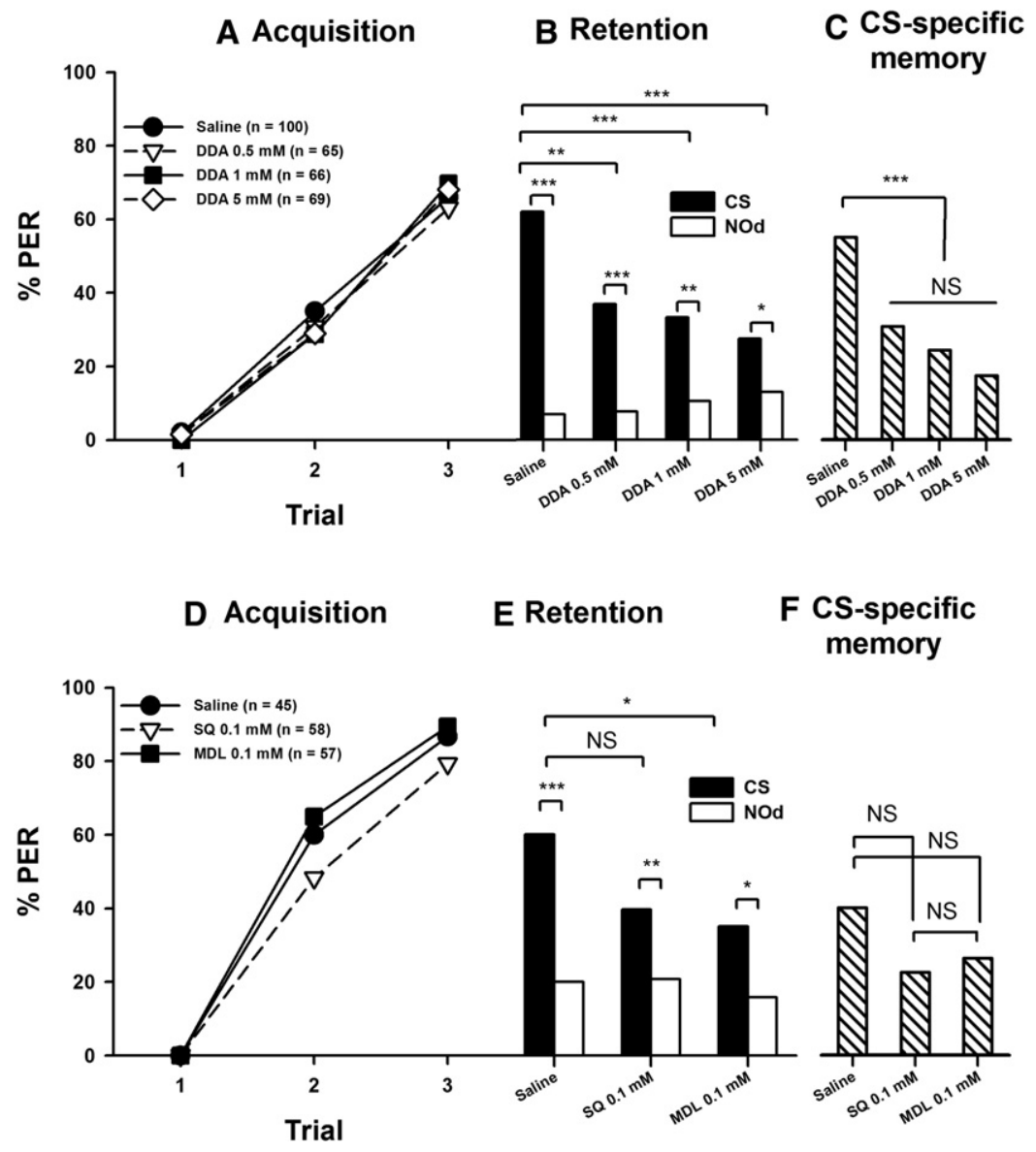

Figure 6. Inhibition of AC impairs 3-d retention. Twenty minutes before conditioning, bees were injected with either saline solution or with an $\mathrm{AC}$ antagonist. $(A-C)$ Performance after injection of three different concentrations $\left(0.5 \mathrm{mM}, 1 \mathrm{mM}\right.$, or $5 \mathrm{mM}$ ) of the $\mathrm{AC}$-inhibitor $2^{\prime}, 5^{\prime}$-dideoxyadenosine (DDA). $(D-F)$ Performance after injection of the two AC inhibitors (0.1 mM each) SQ 22536 and MDL 12330A. (A) All groups showed similar and effective acquisition. (B) In the 3-d retention test, all DDA-injected groups showed a significant decrease of CS responses with respect to the saline control. Drug effects were dose-dependent. Although reduced, CS responses (black bars) were significantly higher than responses to the NOd (white bars) in all groups, thus showing that some CS-specific memory was preserved. (C) Percentage of bees exhibiting CS-specific memory, i.e., responding to the CS and not to the NOd during retention $3 \mathrm{~d}$ after conditioning. (D) All groups showed similar and effective acquisition. (E) In the 3-d retention test, CS responses (black bars) were significantly higher than responses to the NOd (white bars) in all groups. Yet, both AC antagonists induced a decrease of CS responses. This decrease was barely nonsignificant in 22536-injected bees $(P=0.09)$ and significant in MDL 12330 A-injected bees. $(F)$ Percentage of bees exhibiting CS-specific memory, i.e., responding to the $\mathrm{CS}$ and not to the NOd during retention $3 \mathrm{~d}$ after conditioning. Despite the decrease induced by the two AC antagonists, no significant differences were detected. $\left({ }^{*}\right) P<0.05,\left({ }^{* *}\right) P<0.01,\left({ }^{* * *}\right) P<$ 0.001 , (NS) nonsignificant.

not affected by DDA injection (NOd responses, $F_{(3,297)}=0.71$, $P=0.54)$.

Despite the significant decrease in CS responses in all three DDA groups, responses to the CS remained significantly higher than those to the NOd (saline, $\chi^{2}=53.02$, df $=1, P<0.0001$; DDA-62 $0.5 \mathrm{mM}, \chi^{2}=15.43, \mathrm{df}=1, P<0.001$; DDA-62 $1 \mathrm{mM}$, $\chi^{2}=11.53, \mathrm{df}=1, P<0.005 ;$ DDA-62 $5 \mathrm{mM}, \chi^{2}=5.79, \mathrm{df}=1$, $P<0.02)$. The proportion of bees exhibiting CS-specific memory (Fig. 6C) was 55.00\% in the control group, and 30.77\%, 24.24\%, and $17.39 \%$ in the groups injected with DDA at concentrations of $0.5,1$, and $5 \mathrm{mM}$, respectively. CS-specific memory differed between saline-injected and DDA-injected bees $\left(q_{\infty, 4}>3.633\right.$ for all three comparisons, $P<0.001)$ but not between DDA-injected bees $\left(q_{\infty, 4}<3.633\right.$ for all three comparisons, NS).
These results show that inhibition of AC did not affect olfactory learning but decreased CS-specific responses $3 \mathrm{~d}$ after conditioning, without suppressing the capacity to discriminate the CS from the NO.

We verified this conclusion by performing a further experiment with two additional AC antagonists, SQ 22536 (Heinrich et al. 2001) and MDL 12330A (Gray et al. 1984), already assayed in other insect preparations. We injected bees with saline $(n=45)$ or with SQ $22536(n=58)$ or with MDL 12330 A $(n=57) 20$ min before acquisition. Both drugs were delivered at a concentration of $0.1 \mathrm{mM}$ which was chosen based on preliminary experiments.

Figure 6D shows that all three groups of bees learned efficiently the odor-sucrose association $\quad\left(F_{(2,150)}=\right.$ 252.7, $P<0.0001)$. At the third conditioning trial, they reached similar levels of conditioned responses, which varied between $81 \%$ and $89 \%\left(F_{(2,140)}=1.328\right.$, $P=0.268)$. Thus, injection of two further AC inhibitors, SQ 22536 and MDL 12330 A, failed again to impair olfactory acquisition.

The performances of the three groups in the 3 -d retention tests are shown in Figure 6E. Although responses to the CS were significantly higher than those to the NOd in all three groups (saline, $\chi^{2}=16.06, \mathrm{df}=1, P<0.001 ; \mathrm{SQ}$ 22536, $\quad \chi^{2}=6.67, \quad \mathrm{df}=1, \quad P<0.01$; MDL 12330A, $\chi^{2}=5.26, \quad \mathrm{df}=1, \quad P<$ $0.05)$, they varied significantly between groups (CS responses, $F_{(2,157)}=3.57$, $P<0.05)$. Despite the unusual decrease of CS responses from the third conditioning trial to the CS test in the saline group (compare with Fig. 6A,B), salineinjected bees exhibited significantly more CS responses than bees injected with MDL 12330A (Tukey test, $P<$ 0.05). The CS response of the saline-injected bees did not differ from that of the SQ 22536-injected bees but was, nevertheless, close to significance $(P=$ 0.08). SQ 22536- and MDL 12330A-injected bees did not differ from each other in their CS responses $(P=0.87)$. Responses to the NOd were similar in all three groups (NOd responses, $F_{(2,157)}=0.10, P=$ 0.91).

As in the previous experiment with DDA, the proportion of bees exhibiting CS-specific memory was higher in the control group (40\%) than in the SQ 22536- (23\%) and MDL 12330A-injected groups (26\%). Yet, this difference did not reach significance $\left(q_{\infty, 3}<3.314\right.$ for both comparisons, NS). No differences in specific memory were found between AC antagonist-injected groups $\left(q_{\infty, 3}<3.314, \mathrm{NS}\right)$.

Thus, three different AC antagonists yielded comparable results: none of them inhibited olfactory learning but they all affected 3-d retention; they induced a significant decrease of CS responses and a concomitant decrease of CS-specific retention, 
which in the case of DDA was significant and in the case of SQ 22536 and MDL 12330A did not reach significance.

\section{Experiment 7: Blocking of CNG-channel, CaM, CaMKII, and $A C$ signaling impairs late-LTM but neither MTM nor early-LTM}

The previous results indicate that the signaling pathways targeted by the different pharmacological agents assayed are involved in 1-LTM formation. Whether they are also required for earlier memories remains to be determined. As none of the injected drugs affected olfactory acquisition, effects on STM in the minute range (i.e., corresponding to the ITI separating acquisition trials) can be excluded. We thus tested the effects of the drugs at intermediate delays to assess their possible impact on MTM (3 h) and e-LTM $(24 \mathrm{~h})$. Hence, bees were injected $20 \mathrm{~min}$ before conditioning with saline or with the highest tested dose of each drug (L-DIL $1 \mathrm{mM}$ for CNG-channel signaling, W-7 $1 \mathrm{mM}$ for CaM signaling as it was the most effective CaM inhibitor, KN-62 $2 \mathrm{mM}$ for CaMKII signaling, and DDA $5 \mathrm{mM}$ for AC signaling). We then compared retention performances at $3 \mathrm{~h}, 1 \mathrm{~d}$, and $3 \mathrm{~d}$ by focusing on CS-specific memories resulting from each treatment.

Figure 7 shows the proportions of bees responding to the CS but not to the NOd ("CS-specific memory") at the three retention delays ( $3 \mathrm{~h}, 1 \mathrm{~d}, 3 \mathrm{~d}$ ) and for the four drugs assayed. The four drugs significantly reduced CS-specific l-LTM (3 d after conditioning) with respect to controls (Tukey test for multiple comparisons between proportions, $P<0.001$ for all four 3 -d comparisons) (Fig. 7A-D). However, they affected neither CS-specific MTM (3 h) nor CS-specific e-LTM $(1 \mathrm{~d})\left(q_{\infty, 6}<4.03\right.$, NS for all 3-h and 1-day comparisons) (Fig. 7A-D). Thus, blocking signaling through CNG channels, CaMKII, AC, or CaM signaling specifically blocks 1-LTM but affects neither MTM nor e-LTM.

As AC has been suggested as a coincidence detector integrating CS and US inputs (e.g., Gervasi et al. 2010), the results of Figure 7D-but also of Figure 6, A and E-raise interrogations as blocking AC neither affected olfactory acquisition nor the early memory phases (MTM and e-LTM). To determine if this result was specific to the AC antagonist used (DDA), we repeated the experiments of Figure 7D using the two additional AC antagonists assayed in the previous experiment, SQ 22536 and MDL 12330A (Fig. 6D-F). Both were injected at a dose of $0.1 \mathrm{mM} 20 \mathrm{~min}$ before acquisition. Retention performances were recorded $3 \mathrm{~h}$ and $1 \mathrm{~d}$ after conditioning, and compared to those observed at $3 \mathrm{~d}$ after conditioning.

Figure 7, E and F, shows the CS-specific memory at the three retention delays $(3 \mathrm{~h}, 1 \mathrm{~d}, 3 \mathrm{~d})$ for the saline group and the two antagonist-injected groups. Similarly to DDA, SQ 22536 and MDL 12330A neither impaired MTM (3 h after conditioning) nor e-LTM ( $1 \mathrm{~d}$ after conditioning) $\left(q_{\infty, 3}<3.314, P>0.05\right.$ for all comparisons).

Thus, irrespective of the AC antagonist used, AC was dispensable for acquisition and for early memory phases (STM, MTM, e-LTM).

\section{Experiment 8: The effects of injection timing}

To delimit the time window of sensitivity of l-LTM to some of the tested antagonists, we evaluated the effect of different injection times (Fig. 8) for the drugs L-DIL (1 mM), W-7 (1 mM), KN-62 (2 $\mathrm{mM})$, and DDA (5 mM), all of which specifically impaired l-LTM at these doses when injected $20 \mathrm{~min}$ before conditioning (see Fig. 7). In this new experimental series, bees were injected either 90 min before conditioning (Fig. 8A) or 10 min after conditioning (Fig. 8B). In both cases they were tested for retention $3 \mathrm{~d}$ after conditioning. For the bees injected $90 \mathrm{~min}$ before conditioning,
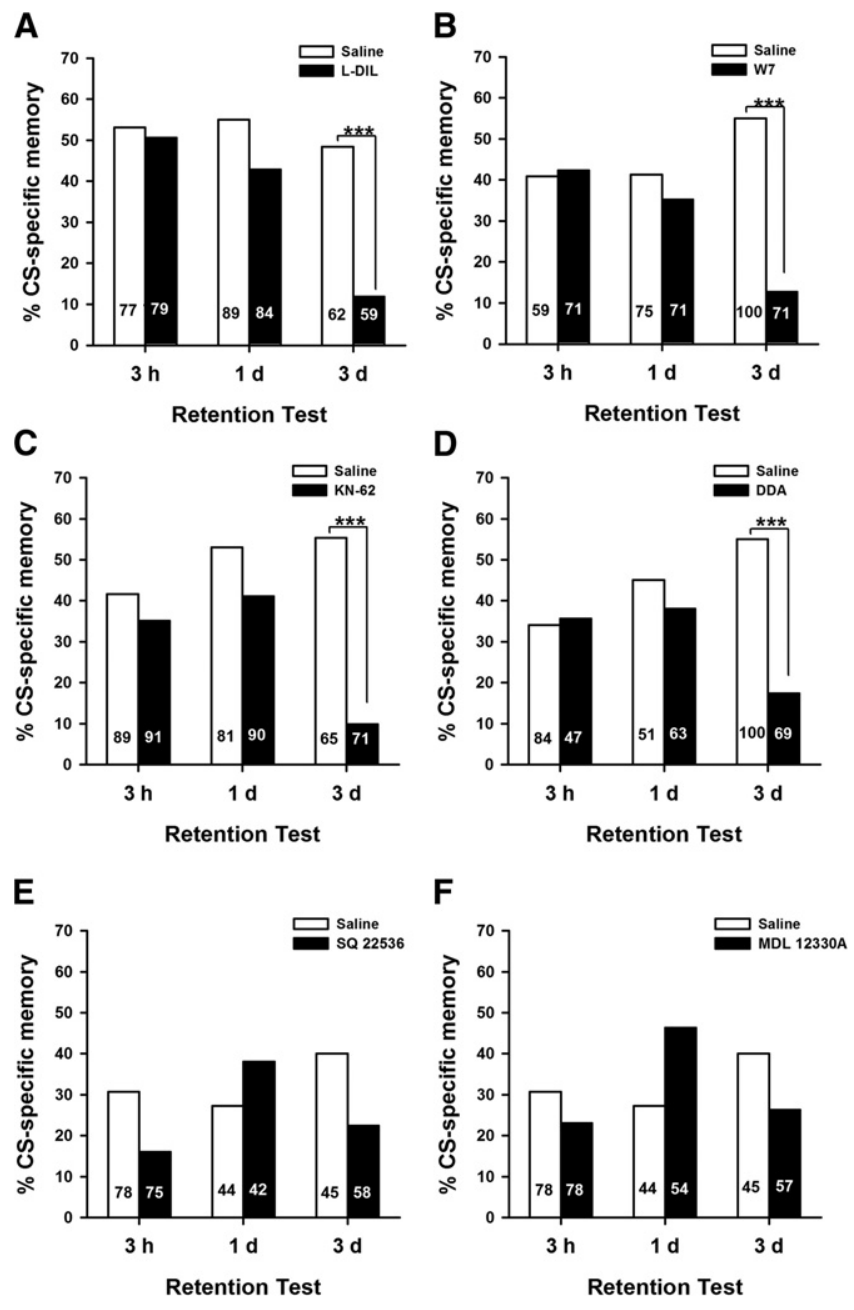

Figure 7. Dependence of CS-specific memory on testing period and injected drug. Twenty minutes before conditioning, animals were injected either with saline solution, or $1 \mathrm{mM} \mathrm{L-DIL}(A), 1 \mathrm{mM} \mathrm{W}-7(B), 2 \mathrm{mM}$ $\mathrm{KN}-62(C), 5 \mathrm{mM}$ DDA $(D), 0.1 \mathrm{mM}$ SQ $22536(E)$, or $0.1 \mathrm{mM} \mathrm{MDL}$ $12330 \mathrm{~A}(F)$. Retention was tested $3 \mathrm{~h}, 1 \mathrm{~d}$, or $3 \mathrm{~d}$ after training. Independent groups of bees were used for each retention period. Data for the 3-d retention tests are the same as in previous figures. CS-specific memory is defined as the percentage of bees which responded to the CS but not to the NOd during the retention test. Four of the six drugs (L-DIL, W-7, KN-62, and DDA) induced a highly significant decrease of CS-specific memory with respect to the saline control only during the 3-d retention test. SQ 22536 and MDL 12330A also induced a decrease of CS-specific memory in the 3 -d retention test but the level of CS-specific memory reached did not differ significantly from that of the saline group. No differences between the drug-injected group and the saline control were found in the 3 -h or the 1 -d retention test. The number of animals tested in the different groups is shown above each data point. (***) $P<0.001$.

two saline controls were run in parallel, one for L-DIL and DDA, and the other for $\mathrm{W}-7$ and $\mathrm{KN}-62$. For the bees injected $10 \mathrm{~min}$ after conditioning, each drug-injected group had its own saline control.

In groups injected with $\mathrm{W}-7, \mathrm{KN}-62$, or DDA 90 min before conditioning (Fig. 8A), CS-specific memory was similar to that of their corresponding saline control $\left(q_{\infty, 3}<3.31\right.$, NS for all three drug vs. control comparisons). In contrast, L-DIL induced a significant decrease of CS-specific l-LTM when injected $90 \mathrm{~min}$ before conditioning $\left(q_{\infty, 3}=4.72, P<0.01\right)$. This result indicates 

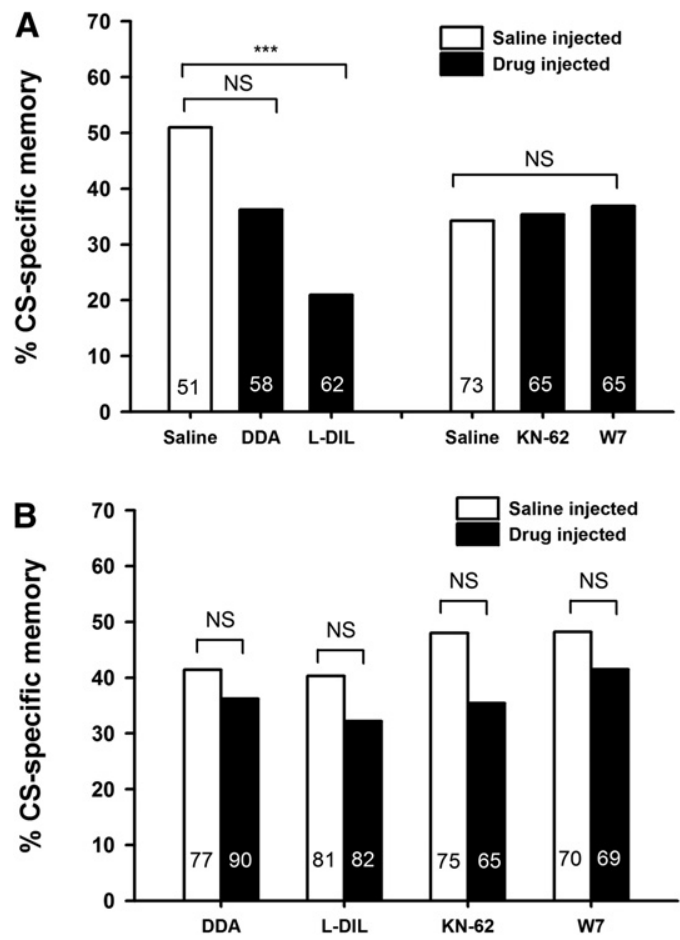

Figure 8. Effect of drug-injection timing on 3-d retention (CS-specific memory). Ninety minutes before conditioning $(A)$ or 10 minutes after conditioning $(B)$, bees were injected with saline solution (white bars) or inhibitors (black bars) (1 mM L-DIL, $1 \mathrm{mM} \mathrm{W}-7,2 \mathrm{mM} \mathrm{KN}-62$, or $5 \mathrm{mM}$ DDA). For the bees injected 90 min before conditioning, two saline controls were run in parallel, one for L-DIL and DDA, and the other for W-7 and $\mathrm{KN}-62$. For the bees injected $10 \mathrm{~min}$ after conditioning, each drug-injected group had its own saline control. Bees were tested $3 \mathrm{~d}$ after training. The sample sizes of each group are indicated within bars. ${ }^{(* *)} P<0.001$, (NS) nonsignificant.

that the effective time window of L-DIL action is longer than those of the other drugs. When injected $10 \mathrm{~min}$ after conditioning, none of the drugs affected CS-specific l-LTM so that responses of the drug-injected bees and the saline-injected bees were similar $\left(q_{\infty, 3}<3.31\right.$, NS for all four drug vs. control comparisons) (Fig. 8B).

Altogether, these results and those shown in Figure 7 indicate that the drugs injected to the bees were effective for blocking l-LTM formation only during a narrow time window, starting with the conditioning (when the odor-sucrose association is first established) and finishing shortly thereafter (as injections $10 \mathrm{~min}$ after conditioning are ineffective). The drugs therefore affect the formation but not the retrieval of l-LTM (which took place in our experiments $72 \mathrm{~h}$ after conditioning).

\section{Discussion}

Our study focused on olfactory learning and memory in the honeybee and aimed at dissecting the contribution of various molecular actors to long-term memory formation. Using the olfactory conditioning of the proboscis extension reflex, we analyzed the performance of 6991 bees injected with different pharmacological inhibitors or saline solution used as a control. We show that $\mathrm{CNG}$ channels, CaM, CaMKII, and AC are involved in the formation of a 3-d specific olfactory memory (l-LTM), but are not required for acquisition, STM, MTM (minutes to hours range), or e-LTM (1 d). Our results show that the induction of these pathways is re- quired during or immediately after conditioning. This is the first comprehensive account demonstrating the involvement of all these molecular actors in the same conditioning protocol (appetitive conditioning of the PER) within the same insect species (the honeybee).

\section{Molecular actors and brain regions in the honeybee}

In the honeybee, several brain regions are involved in olfactory learning and memory and exhibit experience-dependent functional and/or structural plasticity (for reviews, see Menzel 1999, 2001; Giurfa 2007; Giurfa and Sandoz 2012). The antennal lobes (ALs), primary olfactory centers receiving olfactory information from olfactory receptor neurons on the antennae, and the mushroom bodies (MBs), multimodal structures receiving processed olfactory information from the ALs as well as visual, mechanosensory, and gustatory input, are the main candidates for hosting long-term memory traces. Both regions exhibit structural modifications after formation of an olfactory l-LTM (Hourcade et al. 2009, 2010; Arenas et al. 2012).

Consistently, several studies point toward the ALs and the MBs as candidate substrates for molecular events leading to 1-LTM in the bee brain. For instance, NOS is particularly abundant in the ALs and in the MB calyces (Müller 1996) and the NOS gene is strongly expressed in the Kenyon cells, the constitutive MB neurons (Watanabe et al. 2007). NOS activity is detected in the optic lobes, the mushroom bodies, the central body complex, the lateral protocerebral lobes, and the antennal lobes (Watanabe et al. 2007), and PKA activity is increased in a NO-dependent manner in the ALs following multiple-trial olfactory learning (Müller 2000). Higher levels of immunoreactivity for type-II PKA (PKAII) can be found in the MBs compared to other neuropiles (Müller 1997). Accordingly, the gene of a PKA catalytic subunit is predominantly expressed in the MBs (Eisenhardt et al. 2001). The gene of a membrane-bound AC (Amac3) is expressed throughout the brain, but more prominently in the Kenyon cells (Wachten et al. 2006). In Drosophila melanogaster, the AC encoded by the rut gene, which is critical for olfactory learning, is strongly expressed in MB neurons (Han et al. 1992; Crittenden et al. 1998; Zars et al. 2000; Mao et al. 2004; McGuire et al. 2004). Also in Drosophila, a CNG channel-like protein is expressed in AL glomeruli and in the MBs (Miyazu et al. 2000).

The enzymatic activity of CaMKII is enriched in the MBs and central body of the bee compared to the rest of the brain (Kamikouchi et al. 2000). In adults, the phosphorylated form of the enzyme, pCaMKII, is concentrated in a specific subpopulation of Kenyon cells, the noncompact cells (Pasch et al. 2011). Within the olfactory (lip) and visual (collar) subregions of the MB calyx, pCaMKII is colocalized with f-actin in the postsynaptic compartments of the microglomeruli, interaction sites between neurons projecting from primary processing centers (e.g., projection neurons from the ALs) and Kenyon cells. This indicates that pCaMKII is enriched in Kenyon cell dendritic spines, consistent with its potential role in dendritic plasticity. All the molecular actors studied in our work are thus expressed in regions of the bee brain, which have been extensively related with experience-dependent plasticity and associative memory traces.

\section{The role of CAMP-PKA and NO-cGMP signaling pathways in I-LTM formation in honeybees}

Both cAMP-PKA and NO-cGMP signaling pathways play an essential role in LTM formation (Eisenhardt 2006). Previous studies on the role of the NO-cGMP pathway in long-term neural plasticity in the mouse hippocampus (Lu et al. 1999; Lu and Hawkins 
2002) or in nociceptive sensory receptors in Aplysia (Lewin and Walters 1999) suggested that the NO-cGMP pathway acts in parallel with the cAMP-PKA pathway to activate CREB, via PKG, eventually inducing transcription-dependent long-term neural plasticity. Yet, in honeybees, the link proposed between NOcGMP and PKA is lineal (Müller 2000 [see Fig. 5 therein]).

In this insect, the NO system is required for l-LTM formation (Müller 1996). Multiple-trial conditioning leading to l-LTM induces prolonged PKA activation. On the contrary, single-trial conditioning, leading to earlier forms of memory but not to l-LTM, induces only transient PKA activation (Müller 2000). Local imitation of prolonged PKA activation in the ALs, using photorelease of cAMP in combination with a single conditioning trial, is sufficient to induce l-LTM (Müller 2000). This suggests that a training procedure that induces l-LTM leads to the activation of both the NO-cGMP and of the cAMP-PKA signaling pathways (Fig. 9). Additionally, cGMP, which is synthesized from GTP by the soluble guanylyl cyclase (sGC), can directly activate PKA through the RII subunit (Leboulle and Müller 2004).

According to Müller (1996, 2000), both NO-cGMP and PKA signaling are necessary for e-LTM. In our work we did not study the involvement of $\mathrm{NO}-$ cGMP signaling in MTM/e-LTM formation as we did not determine the effect of the NOS antagonist L-NAME or the sGC antagonist ODQ on 3-h- and 24-h retention. Also, we did not use a PKA blocker so we did not assess the effect of PKA on MTM, e-LTM, or l-LTM. Yet, we interfered with AC, which normally activates PKA, and impaired l-LTM, as we observed in all cases a decrease in CS responses. This procedure left, however, e-LTM intact. This result suggests that the PKA activity required for translation-dependent e-LTM might be different from that required for transcription-dependent 1-LTM (Fig. 9). While the latter (termed

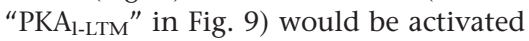
via a specific type of AC downstream of the NO-cGMP signaling pathway (see below), the former (termed "PKA e-LTM" in Fig. 9) could be activated by another AC type intervening on initial CS-US coincidence detection. $\mathrm{PKA}_{\text {l-LTM }}$ downstream of NO-cGMP signaling activates the transcription factor AmCREB inside the nucleus, thus leading to transcriptional processes required for l-LTM. PKA $_{\text {e-LTM }}$ required for translationdependent e-LTM could act outside the nucleus, at the ribosomal level, in order to promote translation directly. This possibility is supported by in vitro experiments showing that rabbit PKA phosphorylates an eEF-2 kinase, which in turn regulates the elongation factor- 2 (eEF-2) that mediates the translocation step in the elongation phase of translation (Redpath and Proud 1993).

Do different PKA forms exist in the honeybee to justify this hypothesis? In the honeybee genome, two genes that encode regulatory subunits (Ampka-r1 and Ampka-r2) and three genes that encode catalytic subunits of PKA (Ampka-c1, Ampka-c2, and Ampka-c3) have been identified (Eisenhardt et al. 2006). The deduced amino acid sequences exhibit different tissue distributions and, among regulatory subunits, functional differences also exist (e.g., the R2 subunit is autophosphorylated while the R1 subunit is not). Long-term memory formation in the bee has been related to PKA with the regulatory subunit R2 and with the catalytic subunit C1 (Fiala et al. 1999; Leboulle and Müller 2004); yet, which catalytic subunits combine with the R2 regulatory subunit and if these combinations are variable and result in different functions is unknown. In any case, the existence of different catalytic and regulatory subunits allows for structural and functional variation in PKA, in agreement with our hypothesis on the existence of PKA $_{\text {e-LTM }}$ and PKA I-LTM. $_{\text {. }}$

This hypothesis could account for the apparent contradiction between our results and those of Müller (2000) who used a PKA antagonist and reported that PKA inhibition before three-

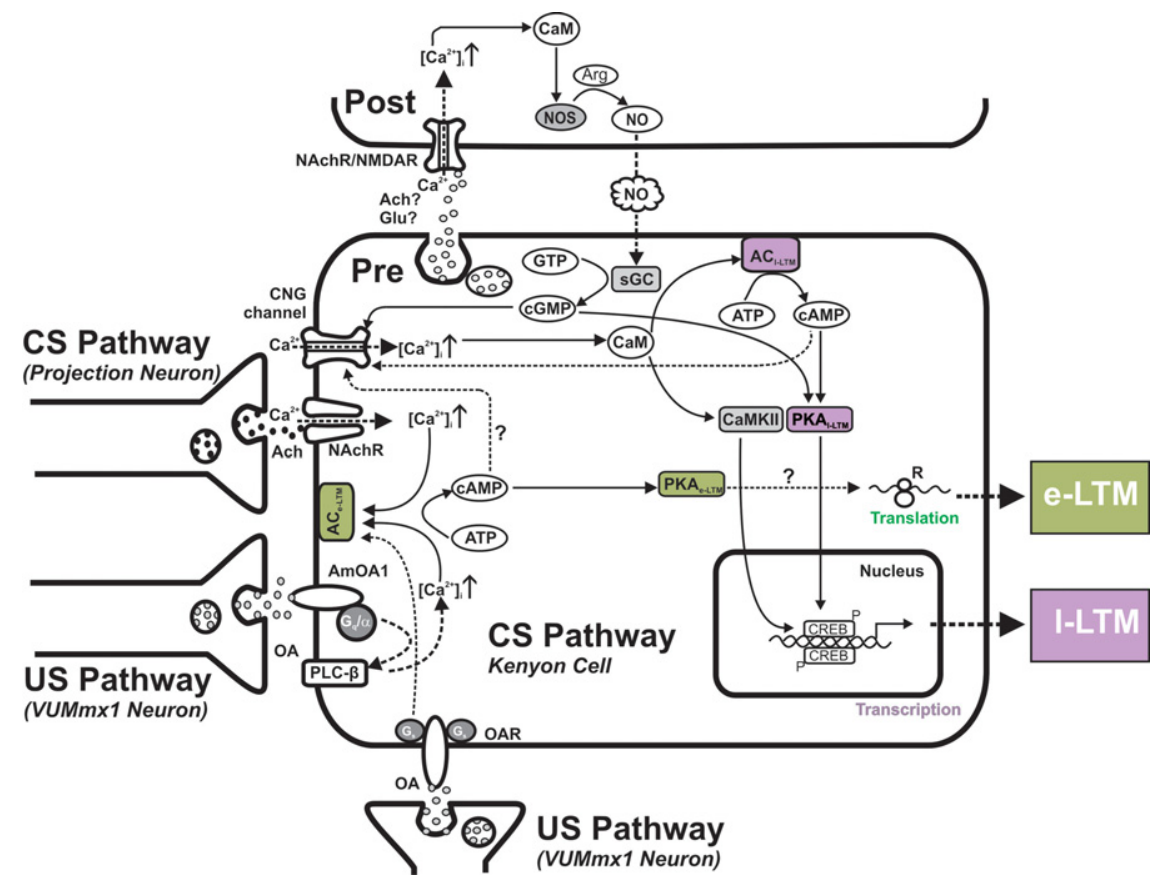

Figure 9. A model of signaling pathways for LTM formation upon associative olfactory conditioning of honeybees. The model is proposed on the basis of the present findings in honeybees and documented findings in insects. It is based on the assumption that NO acts as a retrograde signal in the CS pathway. CS-US associative trials (CS-US coincidence detection is not shown) lead to an increase of intracellular $\mathrm{Ca}^{2+}$ concentration $\left(\left[\mathrm{Ca}^{2+}\right] \mathrm{i}\right)$ via nicotinic acetylcholine (Ach) receptors (NAChRs) (Gauthier 2010) and/or NMDA glutamate (Glu) receptors (NMDARs) (Zannat et al. 2006) in NO-generating neurons (postsynaptic sites). The increased $\left[\mathrm{Ca}^{2+}\right] \mathrm{i}$ activates the NO synthase (NOS) via $\mathrm{Ca}^{2+}$-calmodulin (CaM), leading to NO generation. In NO-receptive neurons (presynaptic sites), soluble guanylyl cyclase (sGC) is stimulated by NO, thereby generating cGMP from GTP. The NOcGMP signaling activates, in turn, PKA (cAMP-dependent protein kinase), which is involved in two different pathways: one, induced by a single CS-US pairing, in which CGMP directly activates PKA with a small amount of cAMP (Leboulle and Müller 2004), leading to transcription-independent e-LTM, and another, induced by multiple CS-US pairings, in which cyclic nucleotide-gated (CNG) channels, $\mathrm{CaM}$, and adenylyl cyclase (AC) are involved, and which leads to transcription-dependent I-LTM. The latter requires CaMKII, which, together with PKA, probably activates CREB (CAMP responsive element binding protein). In the case of mushroom bodies, NO-receptive neurons would correspond to projection neuron afferents from the antennal lobes while NO-generating neurons would correspond to Kenyon cells constituting the mushroom bodies. VUMmx1 (ventral unpaired median neuron of the maxillary neuromere 1 ) is the neuron that mediates reinforcement (sucrose) signaling to olfactory neurons via octopamine (OA) release (Hammer 1993). (CS) conditioned stimulus, (US) unconditioned stimulus, (Arg) arginine, (GTP) guanosine triphosphate, (cGMP) cyclic guanosine monophosphate, (ATP) adenosine triphosphate, (CAMP) cyclic adenosine monophosphate, (PLC) phospholipase C, (AmOA1) octopamine receptor of the honeybee, (OAR) octopamine receptor, $\left(\mathrm{G}_{\mathrm{s}}\right)$ family of $\mathrm{G}$ proteins that stimulate $A C,\left(G_{q}\right)$ family of $G$ proteins that stimulate PLC, $(R)$ ribosome. 
trial olfactory conditioning induces a significant decrease of e-LTM measured $24 \mathrm{~h}$ after conditioning (Müller 2000 [see Fig. 1A therein]). If the PKA antagonist used blocked both types of PKA, then both e-LTM and l-LTM formation would be affected. Note, however, that the decrease in e-LTM found by Müller (2000) upon PKA blockade did not reflect a CS-specific memory as no response to a novel odorant was measured during the tests.

\section{The role of CNG channels in I-LTM formation in honeybees}

The connection between the NO-cGMP and the cAMP-PKA signaling pathways remains unclear. Studies in honeybees (Müller 2000) and crickets (Matsumoto et al. 2006) suggested a sequential organization of these pathways. In crickets, CNG channels and $\mathrm{Ca}^{2+} / \mathrm{CaM}$ seem to intervene between the NO-cGMP and the cAMP-PKA pathways during LTM formation (Matsumoto et al. 2006). Consistently, no indication of PKG involvement in LTM formation was found in honeybees (Müller 2000) or crickets (Matsumoto et al. 2006). We therefore propose that in the honeybee, $\mathrm{CNG}$ channels and $\mathrm{Ca}^{2+} / \mathrm{CaM}$ act as intermediate actors between the NO-cGMP and the cAMP-PKA pathways to induce 1-LTM (Fig. 9).

Specifically, activation of NO-cGMP signaling after multiple-trial conditioning would lead to a binding of cGMP to the CNG channels in the cell membrane, opening them, and making the cell highly permeable to $\mathrm{Ca}^{2+}$. Calcium would then flow into the cell causing a depolarization and ultimately triggering an action potential. Additionally, neuronal excitation could result in activation of an adenylyl cyclase (AC), which would determine an intracellular increase in cAMP; cAMP could also bind to the $\mathrm{CNG}$ channels thereby leading to further $\mathrm{Ca}^{2+}$ influx, depolarization, and action potentials.

The $\mathrm{Ca}^{2+}$ entering through $\mathrm{CNG}$ channels would bind to $\mathrm{CaM}$ and lead to two possible, nonexclusive processes. First, $\mathrm{Ca}^{2+} / \mathrm{CaM}$ may act on AC, which is sensitive to $\mathrm{Ca}^{2+} / \mathrm{CaM}$ and G-protein stimulation (Livingstone et al. 1984; Levin et al. 1992). Stimulation of AC would induce an increase in cAMP levels, thereby providing the basis for prolonged PKA activation underlying l-LTM formation (Müller 2000). Second, $\mathrm{Ca}^{2+} / \mathrm{CaM}$ may directly act on CaMKII, which has also been related to LTM formation (Akalal et al. 2010). The role of these two molecular actors, AC and CaMKII, is discussed in the next sections.

\section{The role of AC in I-LTM formation in honeybees}

Despite its suggested role as coincidence detector in associative learning (Gervasi et al. 2010), our results showed that AC was dispensable for acquisition, STM, MTM, and e-LTM formation (see Figs. 6 and 7). Clearly, both learning and STM, reflected by the response in consecutive conditioning trials spaced by $10 \mathrm{~min}$, were unaffected by AC blockade. Similarly, retention $3 \mathrm{~h}$ and $1 \mathrm{~d}$ after conditioning were also unaffected. This result was unexpected because if AC is a molecular coincidence detector integrating CS and US inputs and thus facilitating associative learning and memory, its inhibition should suppress not only all memory phases but also olfactory learning itself. A possible explanation for our findings is that the lack of suppressive effects of the three AC antagonists used-DDA, SQ 22536, and MDL 12330A—was due to the existence of several ACs with different antagonist affinities and playing different roles for different memory phases. For instance, from the three antagonists used, DDA yielded the clearest effect in the 72-h retention test: all three drugs induced a decrease in CS-specific memory but only the one induced by DDA reached significance.
In Drosophila melanogaster, a total of 10 genes encoding ACs have been identified from which the $\mathrm{Ca}^{2+} / \mathrm{CaM}$-regulated rutabaga (rut) is the best characterized AC enzyme (Livingstone et al. 1984; Levin et al. 1992). In the honeybee, a first gene encoding an AC protein, AmAC3, was identified (Wachten et al. 2006) and its biochemical and pharmacological properties were characterized in vitro (Fuss et al. 2010). Moreover, recent studies indicate the presence of other ACs besides AmAC3 (Balfanz et al. 2012). Bioinformatics and functional expression allowed two additional genes encoding membrane-bound (tm)ACs, AmAC2t and AmAC8, to be characterized. Unlike the common structure of tmACs, AmAC2t lacks the first transmembrane domain. Three additional tmACs and one soluble AC-encoding gene were also identified using bioinformatics (Balfanz et al. 2012). These results indicate that the AC-gene family of the honeybee is comparably as large as that in other species (e.g., Drosophila; see above). Thus, the three inhibitors used may not be equally effective for all existing ACs, targeting only those ACs that intervene in the formation of 1-LTM (termed "AC $\mathrm{C}_{\text {-LTM" }}$ " in Fig. 9) but not those that participate in the formation of earlier memory phases (termed

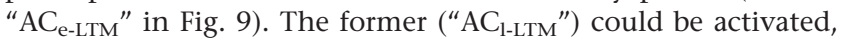
for instance, through multiple spaced conditioning trials, resulting in an increase of PKA activation, which would target the transcription factor CREB (AmCREB) within the cell nucleus (Fig. 9; Eisenhardt et al. 2003). The latter ("AC $\mathrm{e}_{\text {-LTM"), activated, for }}$ instance, through a single conditioning trial, could induce PKA activation, targeting translation at the ribosomal level via an unknown pathway, but not transcription (Fig. 9). Our results thus suggest heterogeneity in the role of different ACs in memory formation and ask for a precise characterization of the different ACs identified so far in the honeybee.

\section{The role of CaMKII in I-LTM formation in honeybees}

$\mathrm{Ca}^{2+} / \mathrm{CaM}$ may directly act on CaMKII, which has been repeatedly related to LTM formation. In the pond snail Lymnaea stagnalis, for instance, CaMKII is necessary for acquisition and late consolidation, but not early or intermediate consolidation or retrieval of LTM (Wan et al. 2010). In Drosophila, CaMKII is necessary for courtship-associated learning and memory (Mehren and Griffith 2004) and for LTM formation following odor-shock pairing (Akalal et al. 2010). In the latter case, flies that experienced spaced odor-shock pairings exhibit an increase in calcium influx into a subclass of Kenyon cells, the $\gamma$ neurons, when tested between 18 and $48 \mathrm{~h}$ after training. This increase relates to the formation of LTM, which occurs between 9 - and 18 -h post-training and persists until 48-h post-training, and is blocked by a dCREB repressor molecule or a CaMKII hairpin RNA (Akalal et al. 2010). Thus, in snails, flies, and bees, protein-dependent forms of LTM require the normal activity of CaMKII.

\section{Molecular cascades and memory phases in honeybees}

In honeybees, several memory phases have been characterized following associative, appetitive olfactory learning (Menzel 1999; Eisenhardt 2006). Both single- and multiple-trial conditioning induce STM in the seconds-to-minutes range, and MTM, in the minutes-to-hours range. Memory induced by a single-trial conditioning decays over time, is sensitive to amnesic treatments (Menzel et al. 1974; Erber et al. 1980), and is independent of translation and transcription. Three-trial conditioning, as performed in our work, induces a stable, long-lasting memory that can be divided into e-LTM, which depends on translation, and l-LTM, which is insensitive to amnesic treatments and requires both translation and transcription (Menzel 1999). Both LTM types are impaired by blocking PKA or the NO-cGMP pathway during conditioning (Müller 2000), but two parallel molecular pathways, 
one leading to e-LTM and the other to l-LTM, seem to be triggered by independent PKA-induced processes during conditioning (Friedrich et al. 2004). The present study provides a further differentiation between these two forms of LTM, namely that l-LTM formation requires CNG channels, calmodulin, AC, and CaMKII, while e-LTM formation does not require, in principle, any of these molecules, although caution is required in the case of AC, as different ACs may intervene in the formation of different memory phases (see Fig. 9). This dissociation may be based on the existence of different subclasses of Kenyon cells expressing or not the key molecular actors necessary for l-LTM formation. For instance, the pCaMKII protein is predominantly concentrated in noncompact Kenyon cells (Pasch et al. 2011). The careful mapping of the studied molecules in the bee brain may allow finding the neurons responsible for e-LTM and l-LTM formation.

Alternatively, all molecules necessary for the formation of different memory phases may be present in all Kenyon cells so that conditioning parameters, such as the stimulation schedule of CS-US pairings, would be critical for the activation of different signaling pathways. For instance, a single conditioning trial (i.e., a single CS-US pairing) would determine the activation of signaling pathways leading to translation and e-LTM (as well as earlier memory phases such as STM and MTM) while multiple spaced conditioning trials could activate, through repetitive CS-US pairings, signaling pathways leading to transcription and l-LTM (Fig. 9).

\section{Addressing CS-specific memories in studies on memory formation}

Most previous experiments on memory retention in bees used absolute conditioning in which a single odor is paired with sucrose reward. Usually, retention tests consisted of one or various presentations of the odor CS, without presenting any novel odorant. This procedure is questionable as the bee's response to the CS may also include some non-CS-specific components (Matsumoto et al. 2012). We therefore want to underline the importance of presenting a novel odor to animals trained in absolute-conditioning protocols, so that the specific contribution of associative memories can be studied. In our experiments, the level of nonspecific responses remained unchanged after most treatments. In only one case did drug-injected bees display a significant increase in their nonspecific response level (injection of CaM blocker R24571) (Fig. 4F). Otherwise, all drugs directly affected the CSspecific component of l-LTM, indicating that they specifically blocked the formation of I-LTM for the CS-US association. Previous studies on bees reported only partial blockade of associative olfactory memory after pharmacological interference with NOS, sGC, PKA, proteases, translation, or transcription (Müller 1996, 2000; Grünbaum and Müller 1998; Wüstenberg et al. 1998). Yet these studies assessed only CS responses during retention so that the drug-resistant LTM component observed could be, in part, nonspecific.

\section{Conclusion}

This work demonstrates the necessity of the NO-cGMP pathway, and of specific molecules, such as cyclic nucleotide-gated channels (CNG), calmodulin (CaM), adenylyl cyclase (AC), and $\mathrm{Ca}^{2+} /$ calmodulin-dependent protein kinase (CaMKII) for the formation of transcription-dependent l-LTM. The emerging model suggests that different pathways, involving different molecular actors, lead to translational and transcriptional processes, and thus to e-LTM and/or l-LTM, after CS-US coincidence detection. Figure 9 illustrates these pathways in the case of a Kenyon cell, an intrinsic neuron of the MBs. Two possibilities are shown for US signaling ("US pathway") through the octopaminergic VUMmx1 neuron, which mediates the reinforcing properties of sucrose solution in the bee brain (Hammer 1993). In one case, octopamine released by VUMmx1 binds to the octopamine $\mathrm{G}_{\mathrm{q}^{-}}$ coupled receptor AmOA1 resulting in an intracellular increase of $\mathrm{Ca}^{2+}$ from internal $\mathrm{Ca}^{2+}$ stores and in a subsequent activation of an $\mathrm{AC}$ ( $\mathrm{AC}_{\mathrm{e}-\mathrm{LTM}}$, see above) involved in the formation of e-LTM; in the other case, octopamine binds to an unknown octopamine receptor $(\mathrm{OAR})$ that is coupled to a $\mathrm{G}_{\mathrm{s}}$-protein activating $\mathrm{AC}_{\mathrm{e}-\mathrm{LTM}}$.

Presynaptic CS signaling to the Kenyon cell occurs via a projection neuron which releases the excitatory neurotransmitter acetylcholine, binding, for instance, to a nicotinic receptor (NAchR) of the Kenyon cell. This binding determines a $\mathrm{Ca}^{2+}$ influx and a subsequent activation of the $\mathrm{AC}_{\mathrm{e}-\mathrm{LTM}}$, which would thus act as a CS-US coincidence detector upon double activation via CS and US signals (Fig. 9). AC activation determines conversion from ATP to cAMP, which in turn activates the PKA specific to the e-LTM pathway $\left(\mathrm{PKA}_{\mathrm{e}-\mathrm{LTM}}\right)$. As suggested above, this PKA might directly regulate translational activity at the ribosome level, supporting e-LTM.

Excitation of the Kenyon cell may lead to release of an excitatory neurotransmitter (acetylcholine or glutamate) to a postsynaptic cell (Grünewald 1999) leading to a retrograde NO neurotransmission back to the Kenyon cell (Müller 1996). This pathway would lead to transcription-dependent l-LTM and would involve the molecular actors studied in our experiments. Thus, $\mathrm{Ca}^{2+}$ influx resulting from acetylcholine or glutamate excitatory neurotransmission would activate $\mathrm{CaM}$, which in turn activates a NO synthase (NOS). NO is synthesized by NOS and diffuses into the Kenyon cell where it activates a soluble guanylyl cyclase (sGC); sGC converts GTP to cGMP, which activates CNG channels, thereby favoring $\mathrm{Ca}^{2+}$ influx, depolarization, and CaM activation. CaM could activate CaMKII on the one hand, and a form of $\mathrm{AC}$ specific to the l-LTM pathway ( $\left.\mathrm{AC}_{\mathrm{l}-\mathrm{LTM}}\right)$ on the other hand. The latter would determine an increase in cAMP and a prolonged activation of a PKA form specifically of this l-LTM pathway $\left(\mathrm{PKA}_{\text {l-LTM }}\right)$. Both CaM-activated pathways would target within the nucleus the transcription factor CREB (AmCREB), thus resulting in de novo protein synthesis required for l-LTM.

This model needs to be tested through a series of experiments that are necessary to confirm or refute the steps proposed in Figure 9. For instance, given that NOS activation precedes CNG activation, with GTP conversion to cGMP via sGC as an intermediate step, blocking NOS and CNG channels should yield the same result as blocking just NOS or CNG channels. Also, inhibition of NOS via L-NAME could theoretically be rescued by cGMP as a CNG channel agonist, or by other substituted cGMP analogs which act as efficient CNG channel agonists (Wei et al. 1998).

Furthermore, as CNG channel activation is upstream of CaM, CaMKII, and $\mathrm{AC}_{\text {l-LTM}} / \mathrm{PKA}$, injection of the CNG channel antagonist L-DIL should remove l-LTM per se so that further injection of $\mathrm{CaM}, \mathrm{CaMKII}$, or $\mathrm{AC}_{\mathrm{l-LTM}} / \mathrm{PKA}$ antagonists should not induce further decreases of 1-LTM. Also, because CaMKII and $\mathrm{AC}_{\text {l-LTM }} / \mathrm{PKA}$ constitute parallel pathways triggered by $\mathrm{CaM}$, injection of the $\mathrm{AC}_{\text {l-LTM }}$ antagonist DDA and of the CaMKII antagonist KN-62 should induce a more drastic, additive reduction of l-LTM.

These experiments are only some examples from a vast possible agenda necessary to unravel the molecular underpinnings of memory formation in honeybees. Some of the features of our model may be wrong in their particulars while some other features may be relevant only under certain experimental conditions pertaining to conditioning schedules and parameters (e.g., CS/US duration and overlap, interstimulus interval, trial number, etc.). Future studies based on the present work will refine and clarify these issues. 


\section{Materials and Methods}

\section{Animals}

Female honeybee workers Apis mellifera caught upon departure from the hive were cooled on ice for $5 \mathrm{~min}$ until they ceased movements. They were then individually harnessed in small metal tubes so that only the head protruded. Mouthparts and antennae could freely move. After being fed with $4 \mu \mathrm{L}$ of a $50 \%$ (weight/ weight) sucrose solution, bees were left undisturbed for $\sim 4$ h. Fifteen minutes before olfactory conditioning, each subject was checked for intact proboscis extension reflex (PER) by lightly touching the antennae with a toothpick imbibed with $50 \%$ sucrose solution without subsequent feeding. Hungry, motivated bees respond to this stimulation by extending reflexively the proboscis (PER) to reach out to and lick the sucrose. Extension of the proboscis beyond the virtual line between the open mandibles was counted as a response. Animals that did not exhibit a PER at this stage were not used in the experiments $(<5 \%)$.

\section{Drugs}

Depending on their solubility in water, drugs were dissolved in either $1 \mu \mathrm{L}$ of honeybee saline solution $(130 \mathrm{mM} \mathrm{NaCl}, 6 \mathrm{mM} \mathrm{KCl}$, $4 \mathrm{mM} \mathrm{MGCl}_{2}, 5 \mathrm{mM} \mathrm{CaCl}_{2}, 160 \mathrm{mM}$ sucrose, $25 \mathrm{mM}$ glucose, $10 \mathrm{mM}$ HEPES; henceforth "saline") or $1 \mu \mathrm{L}$ of saline containing $0.05 \%-0.5 \%$ dimethyl sulfoxide (DMSO). Accordingly, control bees were injected with either $1 \mu \mathrm{L}$ of saline or $1 \mu \mathrm{L}$ of saline containing $0.05 \%-0.5 \%$ DMSO. Injections were performed into the hemolymph of the thorax using a $10-\mu \mathrm{L}$ microsyringe (WPI).

The drugs used were: L-NAME, an inhibitor of NOS, the NO synthase (N $\omega$-nitro-L-arginine methyl ester); ODQ, a soluble guanylyl cyclase (sGC) inhibitor (1H-[1,2,4]oxadiazolo-[4,3a]quinoxalin-1-one); $\mathrm{CHX}$, an inhibitor of protein synthesis (cycloheximide); L-DIL, a CNG channel-inhibitor (L-cis-diltiazem hydrochloride); W-7, TFP, and R24571, three CaM antagonists (N-[6-aminohexyl]-5-chloro-1-naphthalenesulfonamide hydrochloride, trifluoperazine, and calmidazolium, respectively); $\mathrm{KN}$ 62, a CaMKII inhibitor (1-[N,O-bis-(5-isoquinolinesulphonyl)- $\mathrm{N}$ methyl-L-tyrosyl]-4-phenylpiperazine); and three AC inhibitors, DDA, SQ 22536, and MDL 12330A (respectively, 2', 5'-dideoxyadenosine, 9-[tetrahydrofuryl]-adenine, and cis- $\mathrm{N}$-[2-phenylcyclopentyl]-azacyclotridec-1-en-2-amine) (see Table 1).

The doses of L-NAME and ODQ $(1.3 \mathrm{mg} / \mathrm{kg}$ and $0.9 \mathrm{mg} / \mathrm{kg}$ body weight, respectively) were chosen according to previous works in which these drugs acted as efficient NOS and sGC inhibitors in the honeybee nervous system (Müller 1996, 2000). The dose of CHX (140.7 mg/kg body weight) was three times larger than that reported as being ineffective for blocking memory in bees (42 $\mathrm{mg} / \mathrm{kg}$ body weight) (see Wittstock et al. 1993).

Chemicals were purchased from Sigma-Aldrich, except L-DIL (from Biomol), SQ 22536 and MDL 12330A (both from MerckMillipore). ODQ, W-7, R24571, and KN-62 were dissolved in saline containing $0.05 \%-0.5 \%$ DMSO. The other drugs were dissolved in saline alone. Injections were performed 20 or 90 min before, or $10 \mathrm{~min}$ after conditioning. Experimental groups that were run in parallel and that had different drug concentrations, and thus different amounts of DMSO, had a corresponding salinecontrol group which contained the highest amount of DMSO.

\section{Stimulation setup}

For olfactory conditioning, odorants were delivered using an olfactometer sending a constant clean airstream in which odor pulses of known duration could be introduced. Each odorant was applied onto a filter paper placed within a syringe connected to the odor-delivery setup. The airstream was produced by an air pump (Rena Air 400) and directed to the relevant syringes by means of electronic valves (Lee Company S.A.) controlled by a computer. In the absence of odorant stimulation, the airstream passed through a syringe containing a clean piece of filter paper (clean airstream). During olfactory stimulation, the airstream was directed to a syringe containing a filter paper loaded with odorant. After 4-sec stimulation, the airstream was again redirect- ed to the odorless syringe until the next olfactory stimulation. The whole setup was placed in front of an air extractor, which impeded the accumulation of residual odors after delivery of an olfactory stimulus.

\section{Stimuli}

Two odorants, 1-nonanol and 2-hexanol, were used as conditioned stimuli (CS) in a balanced manner, i.e., for half of the bees 1-nonanol was the CS, while for the other half 2-hexanol was the CS. These two odorants are well learned by bees and induce low cross-generalization responses in appetitive olfactory conditioning (Guerrieri et al. 2005). Bees trained with either CS were afterward tested with both odorants-the CS and the novel odor (NOd) - to assess the specificity of the olfactory memories evoked in the retention tests. Fifty percent sugar solution (weight/weight) was used throughout as the unconditioned stimulus (US), and was delivered to the antennae and the proboscis by means of a toothpick.

\section{Conditioning procedure}

Bees injected with different drugs or with saline solution (control bees) were subjected to olfactory conditioning of the proboscis extension response (PER) (Takeda 1961; Bitterman et al. 1983; Giurfa and Sandoz 2012). In this conditioning protocol, the presentation of an odorant immediately before sucrose solution (forward pairing) results in an association between odorant and sucrose that triggers PER in subsequent, nonrewarded retention tests. This effect is clearly associative and involves classical conditioning (Bitterman et al. 1983).

Bees were conditioned during three CS-US trials separated by an inter-trial interval of $10 \mathrm{~min}$. This protocol has been shown to induce the formation of robust LTM in bees (Menzel 1999). Each conditioning trial lasted $30 \mathrm{sec}$. A trial started when a harnessed bee was placed between the olfactometer and an air extractor for $13 \mathrm{sec}$ to allow familiarization with the training situation. Thereafter, the CS was released for $4 \mathrm{sec}$. Three seconds after CS onset, the antennae were stimulated with sucrose solution (US), leading to PER. The bee was allowed to feed for $3 \mathrm{sec}$. Therefore, stimulus overlap was $1 \mathrm{sec}$ and interstimulus interval $3 \mathrm{sec}$. The bee was then left in the conditioning place for $11 \mathrm{sec}$ and then removed.

During each trial, we recorded whether the bee extended its proboscis after CS onset and before US onset (conditioned response). Bees that responded less than twice to the US (out of three presentations) during acquisition, thus exhibiting imperfect unconditioned responses, were excluded from the analyses. They represented $7.7 \%$ of saline-injected bees $(n=2293)$ and $8.9 \%$ of drug-injected bees $(n=4698)$. No differences were ever found in rates of unconditioned responses between drug-treated animals and controls.

\section{Retention tests}

Bees were presented with the CS and with the NOd in order to assess the specificity of the retrieved olfactory memories (Matsumoto et al. 2012). Retention tests were separated by $10 \mathrm{~min}$. Half of the bees first received the CS followed by the NOd while the other half experienced the reversed sequence. Odorant stimulation was identical to that of conditioning trials $(4 \mathrm{sec})$ but no US was given. Retention tests were performed $3 \mathrm{~h}$ (MTM), $1 \mathrm{~d}$ (e-LTM), or $3 \mathrm{~d}$ (l-LTM) after the last conditioning trial. Independent groups of bees were tested at these different periods. After the two retention tests, PER to the US was checked once again. Animals unable to show PER at this point were not considered for the analyses because their lack of response to the odors cannot be necessarily ascribed to a memory deficit but to fatigue.

Bees tested for retention $1 \mathrm{~d}$ or $3 \mathrm{~d}$ after conditioning were subjected to specific handling procedures to ensure survival. Bees tested $1 \mathrm{~d}$ after conditioning were fed until satiation with $50 \%$ sucrose solution and kept in the harnessing tubes until the 
test. Feeding started at least $60 \mathrm{~min}$ after the end of training. Bees tested $3 \mathrm{~d}$ after conditioning were not kept in their tubes until the retention tests as this procedure induces high mortality. They were first painted on the thorax with watercolors allowing individual identification and were then placed in groups of $\sim 30$ individuals in small wooden cages $(65 \times 70 \times 25 \mathrm{~mm})$ containing a diet of food (mixture of 50\% sucrose and 50\% honey) as well as water ad libitum. Cages were kept in a dark and humid box at $33^{\circ} \mathrm{C}$ for $\sim 72 \mathrm{~h}$. On the morning of the third day after conditioning, bees were cooled on ice and reharnessed individually in the metal tubes. Retrieval tests were performed after 5-h food deprivation.

\section{Statistical analysis}

We checked that the treatment neither affected survival nor PER integrity. Only bees that survived the entire experiment and showed a PER to sucrose solution at the end of retention tests (see above) were included in the analyses. In the groups that were subjected to the 3 -d retention test, $21.8 \%$ of the bees died between the end of conditioning and the beginning of the tests (25.4\% in control groups, $20.3 \%$ in drug-injected groups). From the remaining bees, $4.8 \%$ did not show a PER to the US at the end of the retention tests $(6.4 \%$ in control groups, $4.2 \%$ in drug-injected groups). In the groups subjected to the 1-d retention test, $18.5 \%$ of the bees died between the end of conditioning and the beginning of the tests $(20.7 \%$ in control groups, $17.1 \%$ in drug-injected groups). From the remaining bees, $6.8 \%$ did not show a PER to the US at the end of the retention tests ( $3.8 \%$ in control groups, $8.6 \%$ in drug-injected groups).

ANOVA for repeated measurements was used to analyze acquisition performances within or between groups. ANOVA procedures are allowed in the case of binary responses such as PER if comparisons imply equal cell frequencies and at least 40 degrees of freedom of the error term (Lunney 1970). To compare response levels to the CS and the novel odorant in the tests, a McNemar test was used within each group. Multiple comparisons between CS-specific memory levels were performed by means of a Tukey test adapted for proportions, on which a Freeman and Tukey angular transformation was applied (Zar 1999, pp. 563-565). All statistical analyses were carried out using Statistica 5.5 (StatSoft), and differences were considered significant if the $P$-value was $<0.05$.

\section{Acknowledgments}

We thank three anonymous reviewers and G. Isabel (Toulouse) for useful comments and corrections. M.G. thanks U. Müller (Saarbrucken) and D. Eisenhardt (Berlin) for fruitful information exchange and discussions. Y.M. thanks the Fyssen Foundation for postdoctoral support. J.-M.D, J.C.S, and M.G. thank the CNRS and the University Paul Sabatier for financial support. M.G. acknowledges the specific support of a scientific grant of the University Paul Sabatier (Project Apigene) and the valuable support of the Institut Universitaire de France.

\section{References}

Abel T, Nguyen PV, Barad M, Deuel TAS, Kandel ER, Bourtchouladze R. 1997. Genetic demonstration of a role for PKA in the late phase of LTP and in hippocampus-based long-term memory. Cell 88: 615-626.

Akalal DB, Yu D, Davis RL. 2010. A late-phase, long-term memory trace forms in the $\gamma$ neurons of Drosophila mushroom bodies after olfactory classical conditioning. I Neurosci 30: 16699-16708.

Anholt RRH. 1994. Signal integration in the nervous system: adenylate cyclases as molecular coincidence detectors. Trends Neurosci 17: 37-41.

Arenas A, Giurfa M, Sandoz JC, Hourcade B, Devaud JM, Farina WM. 2012. Early olfactory experience induces structural changes in the primary olfactory center of an insect brain. Eur J Neurosci 35: $682-690$.

Balfanz S, Ehling P, Wachten S, Jordan N, Erber J, Mujagic S, Baumann A. 2012. Functional characterization of transmembrane adenylyl cyclases from the honeybee brain. Insect Biochem Mol Biol 42: 435-445.
Bartsch D, Ghirardi M, Skehel PA, Karl KA, Herder SP, Chen M. 1995. Aplysia CREB2 represses long-term facilitation: Relief of repression converts transient facilitation into long-term functional and structural change. Cell 83: 979-992.

Bhattacharya A, Lakhman SS, Singh S. 2004. Modulation of L-type calcium channels in Drosophila via a pituitary adenylyl cyclase-activating polypeptide (PACAP)-mediated pathway. J Biol Chem 279: 37291-37297.

Bitterman ME, Menzel R, Fietz A, Schäfer S. 1983. Classical conditioning of proboscis extension in honeybees (Apis mellifera). J Comp Psychol 97: $107-119$.

Broillet MC, Firestein S. 1996. Gaseous second messengers in vertebrate olfaction. J Neurobiol 30: 49-57.

Busto GU, Cervantes-Sandoval I, Davis RL. 2010. Olfactory learning in Drosophila. Physiology 25: 338-346.

Chen CC, Wu JK, Lin HW, Pai TP, Fu TF, Wu CL, Tully T, Chiang AS. 2012. Visualizing long-term memory formation in two neurons of the Drosophila brain. Science 335: 678-685.

Crittenden JR, Skoulakis EM, Han KA, Kalderon D, Davis RL. 1998. Tripartite mushroom body architecture revealed by antigenic markers. Learn Mem 5: 38-51.

Davis RL. 2005. Olfactory memory formation in Drosophila: from molecular to systems neuroscience. Annu Rev Neurosci 28: 275-302.

Eisenhardt D. 2006. Learning and memory formation in the honeybee (Apis mellifera) and its dependency on the cAMP-protein kinase A pathway. Anim Biol 56: 259-278.

Eisenhardt D, Fiala A, Braun P, Rosenboom H, Kress H, Ebert PR, Menzel R. 2001. Cloning of a catalytic subunit of cAMP-dependent protein kinase from the honeybee (Apis mellifera) and its localization in the brain. Insect Mol Biol 10: 173-181.

Eisenhardt D, Friedrich A, Stollhoff N, Muller U, Kress H, Menzel R. 2003. The AmCREB gene is an ortholog of the mammalian CREB/CREM family of transcription factors and encodes several splice variants in the honeybee brain. Insect Mol Biol 12: 373-382.

Eisenhardt D, Kuhn C, Leboulle G. 2006. The PKA-CREB system encoded by the honeybee genome. Insect Mol Biol 15: 551-561.

Enslen H, Sun P, Brickey D, Soderling SH, Klamo E, Soderling TR. 1994 Characterization of $\mathrm{Ca}^{2+} /$ calmodulin-dependent protein kinase IV. Role in transcriptional regulation. J Biol Chem 269: 15520-15527.

Erber J, Masuhr T, Menzel R. 1980. Localization of short-term memory in the brain of the bee, Apis mellifera. Physiol Entomol 5: 343-358.

Fiala A, Muller U, Menzel R. 1999. Reversible downregulation of PKA during olfatory learning using antisense technique impairs long-term memory formation in the honeybee, Apis mellifera. J Neurosci 19: 10125-10134.

Friedrich A, Thomas U, Muller U. 2004. Learning at different satiation levels reveals parallel functions for the cAMP-protein kinase A cascade in formation of long-term memory. J Neurosci 24: 4460-4468.

Fuss N, Mujagic S, Erber J, Wachten S, Baumann A. 2010. Biochemical properties of heterologously expressed and native adenylyl cyclases from the honeybee brain (Apis mellifera L.). Insect Biochem Mol Biol 40: $573-580$.

Gauthier M. 2010. State of the art on insect nicotinic acetylcholine receptor function in learning and memory. Adv Exp Med Biol 683: 97-115.

Gervasi N, Tchenio P, Preat T. 2010. PKA dynamics in a Drosophila learning center: coincidence detection by rutabaga adenylyl cyclase and spatial regulation by dunce phosphodiesterase. Neuron 65: 516-529.

Giurfa M. 2007. Behavioral and neural analysis of associative learning in the honeybee: a taste from the magic well. J Comp Physiol A 193: $801-824$.

Giurfa M, Sandoz JC. 2012. Invertebrate learning and memory: fifty years of olfactory conditioning of the proboscis extension response in honeybees. Learn Mem 19: 54-66.

Gray DC, Ginsborg BL, House CR. 1984. Cyclic AMP as a possible mediator of dopamine stimulation of cockroach gland cells. QJ Exp Physiol 69: 171-186.

Grünbaum L, Müller U. 1998. Induction of a specific olfactory memory leads to a long-lasting activation of protein kinase $\mathrm{C}$ in the antennal lobe of the honeybee. J Neurosci 18: 4384-4392.

Grünewald B. 1999. Physiological properties and response modulations of mushroom body feedback neurons during olfactory learning in the honeybee Apis mellifera. J Comp Physiol A 185: 565-576.

Guerrieri F, Schubert M, Sandoz JC, Giurfa M. 2005. Perceptual and neural olfactory similarity in honeybees. PLoS Biol 3: e60.

Hammer M. 1993. An identified neuron mediates the unconditioned stimulus in associative olfactory learning in honeybees. Nature 366: 59-63.

Han PL, Levin LR, Reed RR, Davis RL. 1992. Preferential expression of the Drosophila rutabaga gene in mushroom bodies, neural centers for learning in insects. Neuron 9: 619-627.

Heinrich R, Wenzel B, Elsner N. 2001. A role for muscarinic excitation: control of specific singing behavior by activation of the adenylate 
cyclase pathway in the brain of grasshoppers. Proc Natl Acad Sci 98: 9919-9923.

Hourcade B, Perisse E, Devaud JM, Sandoz JC. 2009. Long-term memory shapes the primary olfactory center of an insect brain. Learn Mem 16: $607-615$.

Hourcade B, Muenz TS, Sandoz JC, Rossler W, Devaud JM. 2010. Long-term memory leads to synaptic reorganization in the mushroom bodies: a memory trace in the insect brain? J Neurosci 30: 6461-6465.

Kamikouchi A, Takeuchi H, Sawata M, Natori S, Kubo T. 2000. Concentrated expression of $\mathrm{Ca}^{2+} /$ calmodulin-dependent protein kinase II and protein kinase $\mathrm{C}$ in the mushroom bodies of the brain of the honeybee Apis mellifera L. J Comp Neurol 417: 501-510.

Kandel ER. 2001. The molecular biology of memory storage: a dialogue between genes and synapses. Science 294: 1030-1038.

Kaupp UB, Seifert R. 2002. Cyclic nucleotide-gated ion channels. Physiol Rev 82: 769-824.

Kelliher KR, Ziesmann J, Munger SD, Reed RR, Zufall F. 2003. Importance of the CNGA4 channel gene for odor discrimination and adaptation in behaving mice. Proc Natl Acad Sci 100: 4299-4304.

Kemenes I, Kemenes G, Andrew RJ, Benjamin PR, O'Shea M. 2002. Critical time-window for NO-cGMP-dependent long-term memory formation after one-trial appetitive conditioning. J Neurosci 22: 1414-1425.

Leboulle G, Müller U. 2004. Synergistic activation of insect cAMP-dependent protein kinase A (type II) by cyclic AMP and cyclic GMP. FEBS Lett 576: 216-220.

Levin LR, Han PL, Hwang PM, Feinstein PG, Davis RL, Reed RR. 1992. The Drosophila learning and memory gene rutabaga encodes a $\mathrm{Ca}^{2+} /$ calmodulin-responsive adenylyl cyclase. Cell 68: 479-489.

Lewin MR, Walters ET. 1999. Cyclic GMP pathway is critical for inducing long-term sensitization of nociceptive sensory neurons. Nat Neurosci 2: $18-23$.

Limback-Stokin K, Korzus E, Nagaoka-Yasuda R, Mayford M. 2004. Nuclear calcium/calmodulin regulates memory consolidation. J Neurosci 24: 10858-10867.

Livingstone MS, Sziber PP, Quinn WG. 1984. Loss of calcium/calmodulin responsiveness in adenylate cyclase of rutabaga, a Drosophila learning mutant. Cell 37: 205-215.

Lu YF, Hawkins RD. 2002. Ryanodine receptors contribute to cGMP-induced late-phase LTP and CREB phosphorylation in the hippocampus. J Neurophysiol 88: 1270-1278.

Lu YF, Kandel ER, Hawkins RD. 1999. Nitric oxide signaling contributes to late-phase LTP and CREB phosphorylation in the hippocampus. $J$ Neurosci 19: 10250-10261.

Lunney GH. 1970. Using analysis of variance with a dichotomous dependent variable: an empirical study. J Educ Meas 7: 263-269.

Makhinson M, Chotiner JK, Watson JB, O'Dell TJ. 1999. Adenylyl cyclase activation modulates activity-dependent changes in synaptic strength and $\mathrm{Ca}^{2+}$ /calmodulin-dependent kinase II autophosphorylation. J Neurosci 19: 2500-2510.

Malenka RC, Kauer JA, Perkel DJ, Mauk MD, Kelly PT, Nicoll RA, Waxham MN. 1989. An essential role for postsynaptic calmodulin and protein-kinase activity in long-term potentiation. Nature 340: 554-557.

Malik BR, Gillespie JM, Hodge JJL. 2013. CASK and CaMKII function in the mushroom body $\alpha / \beta$ neurons during Drosophila memory formation. Front Neural Circuits 7: 52.

Mao Z, Roman G, Zong L, Davis RL. 2004. Pharmacogenetic rescue in time and space of the rutabaga memory impairment by using gene-switch. Proc Natl Acad Sci 101: 198-203.

Margrie TW, Rostas JAP, Sah P. 1998. Presynaptic long-term depression at a central glutamatergic synapse: a role for CaMKII. Nat Neurosci 1: 378-383.

Margulies C, Tully T, Dubnau J. 2005. Deconstructing memory in Drosophila. Curr Biol 15: R700-R713.

Matsumoto Y, Unoki S, Aonuma H, Mizunami M. 2006. Critical role of nitric oxide-cGMP cascade in the formation of cAMP-dependent long-term memory. Learn Mem 13: 35-44.

Matsumoto Y, Menzel R, Sandoz JC, Giurfa M. 2012. Revisiting olfactory classical conditioning of the proboscis extension response in honey bees: a step towards standardized procedures. J Neurosci Methods 211: $159-167$.

McGuire SE, Mao Z, Davis RL. 2004. Spatiotemporal gene expression targeting with the TARGET and gene-switch systems in Drosophila. Sci STKE 2004: pl6.

Mehren JE, Griffith LC. 2004. Calcium-independent calcium/ calmodulin-dependent protein kinase II in the adult Drosophila CNS enhances the training of pheromonal cues. J Neurosci 24: 10584-10593.

Menzel R. 1999. Memory dynamics in the honeybee. J Comp Physiol A 185: $323-340$.
Menzel R. 2001. Searching for the memory trace in a mini-brain, the honeybee. Learn Mem 8: 53-62.

Menzel R, Erber J, Masuhr T. 1974. Learning and memory in the honeybee. In Experimental analysis of insect behaviour (ed. Barton-Browne L), pp. 195-217. Springer, Berlin, Germany.

Micheau J, Riedel G. 1999. Protein kinases: Which one is the memory molecule? Cell Mol Life Sci 55: 534-548.

Miyazu M, Tanimura T, Sokabe M. 2000. Molecular cloning and characterization of a putative cyclic nucleotide-gated channel from Drosophila melanogaster. Insect Mol Biol 9: 283-292.

Müller U. 1996. Inhibition of nitric oxide synthase impairs a distinct form of long-term memory in the honeybee, Apis mellifera. Neuron 16: $541-549$.

Müller U. 1997. Neuronal cAMP-dependent protein kinase type II is concentrated in mushroom bodies of Drosophila melanogaster and the honeybee Apis mellifera. J Neurobiol 33: 33-44.

Müller U. 2000. Prolonged activation of cAMP-dependent protein kinase during conditioning induces long-term memory in honeybees. Neuron 27: $159-168$

Nakazawa H, Kaba H, Higuchi T, Inoue S. 1995. The importance of calmodulin in the accessory olfactory bulb in the formation of an olfactory memory in mice. Neuroscience 69: 585-589.

Pasch E, Muenz TS, Rössler W. 2011. CaMKII is differentially localized in synaptic regions of Kenyon cells within the mushroom bodies of the honeybee brain. J Comp Neurol 519: 3700-3712.

Poser S, Storm DR. 2001. Role of $\mathrm{Ca}^{2+}$-stimulated adenylyl cyclases in LTP and memory formation. Int J Dev Neurosci 19: 387-394.

Redpath NT, Proud CG. 1993. Cyclic AMP-dependent protein kinase phosphorylates rabbit reticulocyte elongation factor-2 kinase and induces calcium-independent activity. Biochem J 293: 31-34.

Schwärzel M, Müller U. 2006. Dynamic memory networks: dissecting molecular mechanisms underlying associative memory in the temporal domain. Cell Mol Life Sci 63: 989-998.

Shan Q, Chan GCK, Storm DR. 2008. Type 1 adenylyl cyclase is essential for maintenance of remote contextual fear memory. J Neurosci 28: 12864-12867.

Takeda K. 1961. Classical conditioned response in the honey bee. J Insect Physiol 6: 168-179.

Wachten S, Schlenstedt J, Gauss R, Baumann A. 2006. Molecular identification and functional characterization of an adenylyl cyclase from the honeybee. J Neurochem 96: 1580-1590.

Wan HM, Mackay B, Iqbal H, Naskar S, Kemenes G. 2010. Delayed intrinsic activation of an NMDA-independent CaM-kinase II in a critical time window is necessary for late consolidation of an associative memory. $J$ Neurosci 30: 56-63.

Wang H, Ferguson GD, Pineda VV, Cundiff PE, Storm DR. 2004. Overexpression of type-1 adenylyl cyclase in mouse forebrain enhances recognition memory and LTP. Nat Neurosci 7: 635-642.

Watanabe T, Kikuchi M, Hatakeyama D, Shiga T, Yamamoto T, Aonuma H, Takahata M, Suzuki N, Ito E. 2007. Gaseous neuromodulator-related genes expressed in the brain of honeybee Apis mellifera. Dev Neurobiol 67: $456-473$.

Wei JY, Cohen ED, Genieser HG, Barnstable CJ. 1998. Substituted cGMP analogs can act as selective agonists of the rod photoreceptor cGMP-gated cation channel. J Mol Neurosci 10: 53-64.

Wittstock S, Kaatz HH, Menzel R. 1993. Inhibition of brain protein synthesis by cycloheximidine does not affect formation of long-term memory in honeybees after olfactory conditioning. J Neurosci 13: $1379-1386$.

Wong ST, Athos J, Figueroa XA, Pineda VV, Schaefer ML, Chavkin CC, Muglia LJ, Storm DR. 1999. Calcium-stimulated adenylyl cyclase activity is critical for hippocampus-dependent long-term memory and late phase LTP. Neuron 23: 787-798.

Wüstenberg D, Gerber B, Menzel R. 1998. Long- but not medium-term retention of olfactory memory in honeybees is impaired by actinomycin D and anisomycin. Eur J Neurosci 10: 2742-2745.

Yin JCP, Tully T. 1996. CREB and the formation of long-term memory. Curr Opin Neurobiol 6: 264-268.

Zannat MT, Locatelli F, Rybak J, Menzel R, Leboulle G. 2006. Identification and localisation of the NR1 sub-unit homologue of the NMDA glutamate receptor in the honeybee brain. Neurosci Lett 398: 274-279.

Zar JH. 1999. Biostatistical analysis. Prentice Hall, London, UK.

Zars T, Wolf R, Davis R, Heisenberg M. 2000. Tissue-specific expression of a Type I adenylyl cyclase rescues the rutabaga mutant memory defect: in search of the engram. Learn Mem 7: 18-31.

Received June 6, 2013; accepted in revised form February 20, 2014. 


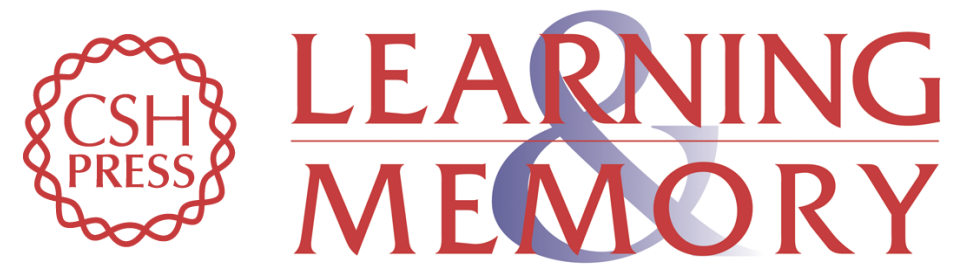

\section{Cyclic nucleotide-gated channels, calmodulin, adenylyl cyclase, and calcium/calmodulin-dependent protein kinase II are required for late, but not early, long-term memory formation in the honeybee}

Yukihisa Matsumoto, Jean-Christophe Sandoz, Jean-Marc Devaud, et al.

Learn. Mem. 2014, 21:

Access the most recent version at doi:10.1101//m.032037.113

References This article cites 83 articles, 28 of which can be accessed free at: http://learnmem.cshlp.org/content/21/5/272.full.html\#ref-list-1

Creative This article is distributed exclusively by Cold Spring Harbor Laboratory Press for the Commons first 12 months after the full-issue publication date (see

License http://learnmem.cshlp.org/site/misc/terms.xhtml). After 12 months, it is available under a Creative Commons License (Attribution-NonCommercial 4.0 International), as described at http://creativecommons.org/licenses/by-nc/4.0/.

Email Alerting Receive free email alerts when new articles cite this article - sign up in the box at the Service top right corner of the article or click here. 